\title{
Conservation and divergence of mitochondrial apoptosis pathway in the Pacific oyster, Crassostrea gigas
}

\author{
Yingxiang Li $\mathrm{Li}^{1,2,3}$, Linlin Zhang ${ }^{1,2,3}$, Tao Qu ${ }^{1,2,3}$, Xueying Tang ${ }^{1,2,3,4}$, Li Li ${ }^{*, 1,2,3}$ and Guofan Zhang ${ }^{*, 1,2,3}$
}

Apoptosis is considered a crucial part of the host defense system in oysters according to previous reports; however, the exact process by which this occurs remains unclear. Besides, mitochondrial apoptosis is the primary method of apoptosis in vertebrate cells, but has been poorly studied in invertebrates and is quite controversial. In this study, we investigated the molecular mechanism of mitochondrial apoptosis in the Pacific oyster Crassostrea gigas. Notably, we show that most key elements involved in the vertebrate mitochondrial apoptosis pathway - including mitochondrial outer membrane permeabilization, cytochrome $\mathrm{C}$ release, and caspase activation - are also present in C. gigas. In contrast, the lack of Bcl-2 homology 3-only subfamily members and apoptotic protease activating factor-1 (APAF-1) protein revealed evolutionary diversity from other phyla. Our results support that mitochondrial apoptosis in animals predates the emergence of vertebrates, but suggest that an unexpectedly diverse mitochondrial apoptosis pathway may exist in invertebrates. In addition, our work provided new clues for an improved understanding of how bivalve acclimate themselves to an inconstant environment.

Cell Death and Disease (2017) 8, e2915; doi:10.1038/cddis.2017.307; published online 6 July 2017

Oysters live in estuarine and intertidal zones and are constantly exposed to fluctuating temperatures, variable salinity, toxic metals, and desiccation because of their sessile behavior. ${ }^{1}$ Apoptosis is involved in the response to various stressors and an important host defense mechanism in oysters. For instance, apoptosis participates in the oyster's defense to Perkinsus marinus, an intracellular protozoan that can cause lethal infection. ${ }^{2}$ Others have also shown that exposure to cadmium and copper elevates apoptosis levels in oysters. ${ }^{3,4}$ The recent application of high-throughput sequencing in marine biology studies has revealed the extensive involvement of apoptosis-related genes in various stress responses, including those to virus, ${ }^{5}$ air exposure, ${ }^{1}$ hyperthermia, ${ }^{6}$ and low salinity. ${ }^{7}$ However, no studies have focused on elucidating the molecular pathways regulating apoptosis in oyster and the exact physiological mechanisms remain vague, hindering our understanding of how this sedentary animal adapts to its fickle environment.

The mitochondrial or intrinsic apoptosis pathway is characterized by the participation of mitochondria in apoptotic signaling and has been extensively described in vertebrates, including mammals ${ }^{8,9}$ and amphibians. ${ }^{10,11}$ Several genes homologous to mammalian apoptosis effectors have been identified in invertebrates in recent years, ${ }^{12-15}$ seemingly indicative of the existence of a mitochondrial apoptosis pathway in these species.

In comparison with the breadth of data on the molecular physiology of mammalian mitochondrial apoptosis, relatively few mechanisms in invertebrates have been elucidated. ${ }^{16-19}$
Nevertheless, current evidence suggests an increased diversity of pathway effectors in these species. For instance, mitochondrial outer membrane permeabilization (MOMP) and cytochrome $c$ release - hallmarks of vertebrate mitochondrial apoptosis - had no role in mitochondrial apoptosis in the nematode Caenorhabditis elegans. ${ }^{16}$ More specifically, cell death protein 4 - the $C$. elegans apoptotic protease activating factor-1 (APAF-1) homolog - lacks the WD domain responsible for its interaction with cytochrome $c .{ }^{16}$ Similarly, although the Drosophila APAF-1-related killer (ARK) homolog contains this region, ${ }^{17}$ no biochemical evidence exists on the involvement of cytochrome $c$ in ARK activation and induction of the apoptosis cascade. ${ }^{20}$ As such, additional work is needed to determine the extent of this diversity in invertebrate mitochondrial apoptosis and further understand the pathway's evolution in animals.

Cursory studies on bivalve apoptosis have been performed, ${ }^{21-25}$ yet the exact mechanism of mitochondrial apoptosis remains unclear. This study has three specific goals and therefore includes three aspects of work. First, to investigate whether MOMP and cytochrome $c$ are involved in mitochondrial apoptosis of oyster, we tested the mitochondrial membrane potential (MMP) and subcellular distribution of cytochrome $c$ in UV-irradiated oyster hemocytes. Second, to examine whether members of oyster caspase family regulate mitochondrial apoptosis, activities of caspase 9 and caspase 3 in hemocytes and cytosolic extracts of oyster upon distinct treatments were measured. Third, to elucidate the regulatory roles of $\mathrm{Bcl}-2$ family and p53 in mitochondrial apoptosis

\footnotetext{
${ }^{1}$ Key Laboratory of Experimental Marine Biology, Institute of Oceanology, Chinese Academy of Sciences, Qingdao, China; ${ }^{2}$ Laboratory for Marine Biology and Biotechnology, Qingdao National Laboratory for Marine Science and Technology, Qingdao, China; ${ }^{3}$ National \& Local Joint Engineering Laboratory of Ecological Mariculture, Institute of Oceanology, Chinese Academy of Sciences, Qingdao, China and ${ }^{4}$ University of Chinese Academy of Sciences, Beijing, China

${ }^{*}$ Corresponding author: L Li or G Zhang, Key Laboratory of Experimental Marine Biology, Institute of Oceanology, Chinese Academy of Sciences, No.7 Nanhai Road, Qingdao 266071, China. Tel: +86 53282896728 or +86 532 82898701; Fax: +86 53282898701 (G.H); E-mail: lili@qdio.ac.cn or gfzhang@ qdio.ac.cn

Received 14.12.16; revised 27.5.17; accepted 31.5.17; Edited by G Melino
} 
pathway of oyster, multiple functional assays were performed. Given that oyster cell lines are not widely available currently, mammalian and yeast cells were used in several assays as molecular tools, which is a typical practice for species without established cell lines. ${ }^{18,19,26}$ Our work significantly improves mechanism understanding of mitochondrial apoptosis pathway in the Pacific oyster and expands our knowledge of evolutionary diversity of apoptosis system in invertebrates.

\section{Results}

UV irradiation results in loss of MMP and cytochrome $c$ release in Crassostrea gigas. UV irradiation is an effective apoptosis-inducing factor in many species, including bivalves. ${ }^{25,27-29}$ Thus, we irradiated $C$. gigas hemocytes with UV light and found a markedly higher percentage of apoptotic cells when compared with non-irradiated controls (Figure 1a). In addition, transmission electron microscopy (TEM) analysis showed the presence of apoptotic cells under UV light irradiation (Supplementary Fig S1), further indicating that UV irradiation was an efficacious apoptosis-inducing factor in $C$. gigas.

The loss of MMP $(\Delta \psi \mathrm{m})$ is an indication of early stage of apoptosis, as it is associated with MOMP in vertebrates. ${ }^{30}$ Thus, we examined MMP with JC-1 assays to determine whether mitochondrial apoptosis in Pacific oyster involved an increase in mitochondrial outer membrane permeability. Notably, irradiated hemocytes exhibited a significant decrease in MMP at $6 \mathrm{~h}$ post irradiation (hpi), which further decreased at 9 hpi and 24 hpi (Figure 1b), indicating the existence of an MOMP-like process in UV irradiation-induced apoptosis in C. gigas.

Vertebrate MOMP results in cytochrome $c$ release and triggers mitochondria-mediated apoptosis. To determine whether cytochrome $c$ release occurred in $C$. gigas cells, UV-irradiated hemocytes were subjected to cytosolic/mitochondrial subcellular fractionation at $24 \mathrm{hpi}$ and the presence of cytochrome $c$ was assessed in each fraction. Western blot analysis revealed that cytochrome $c$ was found in the cytosolic protein fraction of irradiated cells, but undetectable in that of untreated cells (Figure 1c), suggesting that UV irradiation induced release of cytochrome $c$ from mitochondria to the cytosol.

Cytochrome c activates caspase 9 and caspase 3 activity. We tested the activities of effector caspase 9 and executioner caspase 3 in oyster hemocytes following UV irradiation and found remarkable elevations in the activity levels of both caspases at 20 hpi (Figures 2a and b), indicating the involvement of $C$. gigas $(\mathrm{Cg})$-caspase 9 and Cg-caspase 3 in irradiation-induced apoptosis. We then incubated cytosolic extracts with cytochrome $c$ purified from equine hearts or $C$. gigas $(\mathrm{Cg}-\mathrm{Cyt} C$ ). Notably, both $\mathrm{Cg}$ caspase 9 and $\mathrm{Cg}$-caspase 3 activity was significantly increased in the presence of cytochrome $c$ from either source (Figures 2c and d). Further, the addition of exogenous deoxyadenosine triphosphate (dATP) enhanced the cytochrome $c$-mediated-activation of both caspases (Figures $2 \mathrm{c}$ and $\mathrm{d}$ ).

To determine whether $\mathrm{Cg}$-caspase 3 activity was dependent on that of Cg-caspase 9, oyster cytosolic extracts were pretreated with the caspase 9 inhibitor Z-LEHD-FMK before a

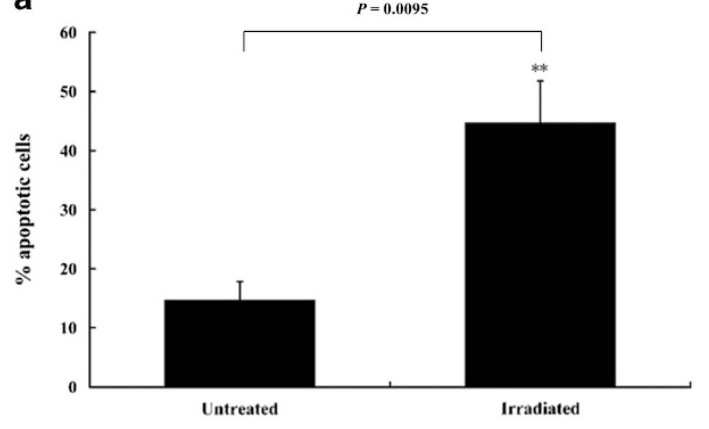

c

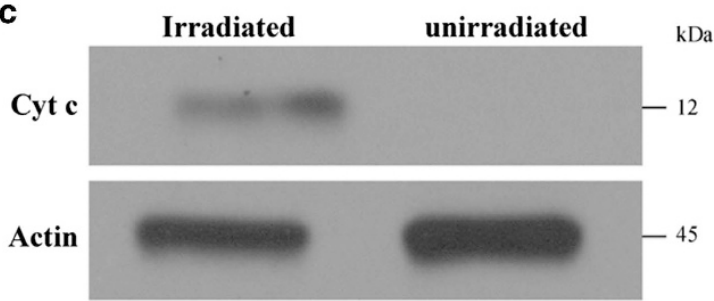

b

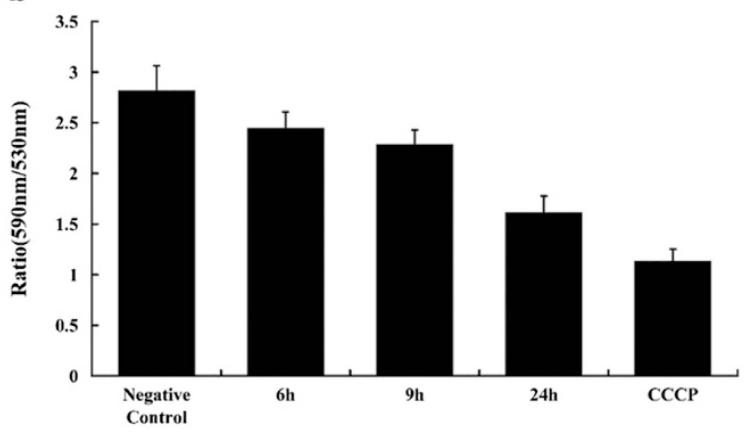

Figure 1 Analysis of apoptosis, mitochondrial membrane potential (MMP), and cytochrome $c$ release in UV-irradiated hemocytes of $C$. gigas. (a) Oyster hemocytes were irradiated with UV light and apoptosis was monitored by Annexin V/propidium iodide (PI) immunostaining at $20 \mathrm{~h}$ post irradiation (hpi). Data are shown as the mean \pm S.D. $(N=6)$. ${ }^{* *} P<0.01$. (b) Oyster hemocytes were UV-irradiated or treated with $10 \mu \mathrm{M}$ carbonylcyanide-p-chlorophenyl hydrazone (CCCP), and hemocyte MMP was measured by JC-1 assay. Irradiated cells were sampled and measured at $6 \mathrm{hpi,} 9 \mathrm{hpi}$, and $24 \mathrm{hpi}$. CCCP-treated and untreated/non-irradiated cells served as positive and negative controls, respectively. Lower $590 / 530 \mathrm{~nm}$ ratios refer to lower $\Delta \Psi \mathrm{m}$. $N=6$ per time point (including negative control and CCCP group), data are shown as the mean \pm S.D. (c) Cytosolic proteins were extracted from irradiated ( $24 \mathrm{hpi}$ ) and non-irradiated oyster hemocytes and analyzed by western blot using anti-cytochrome $c$ and anti-actin antibodies 
a

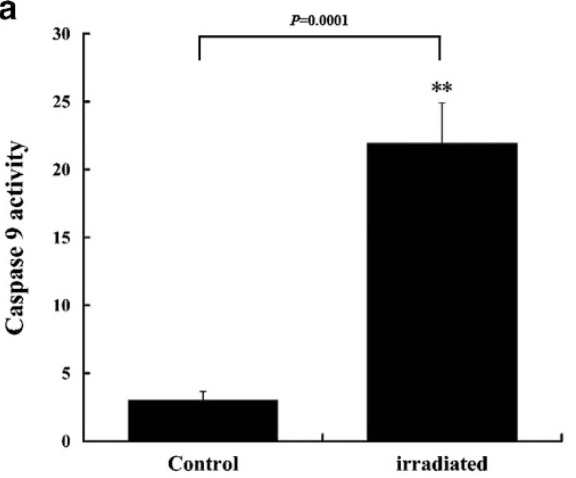

C

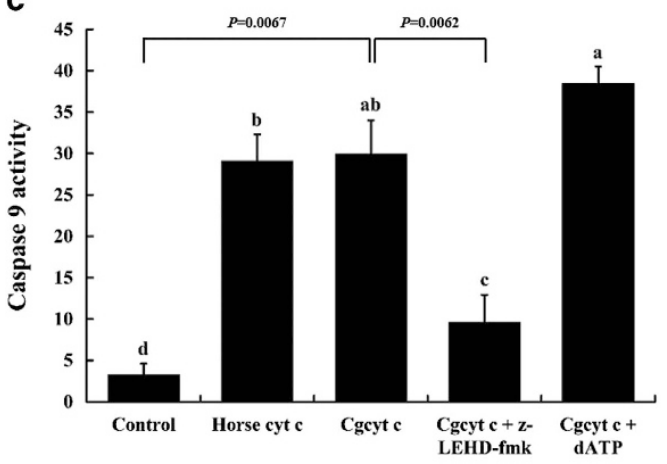

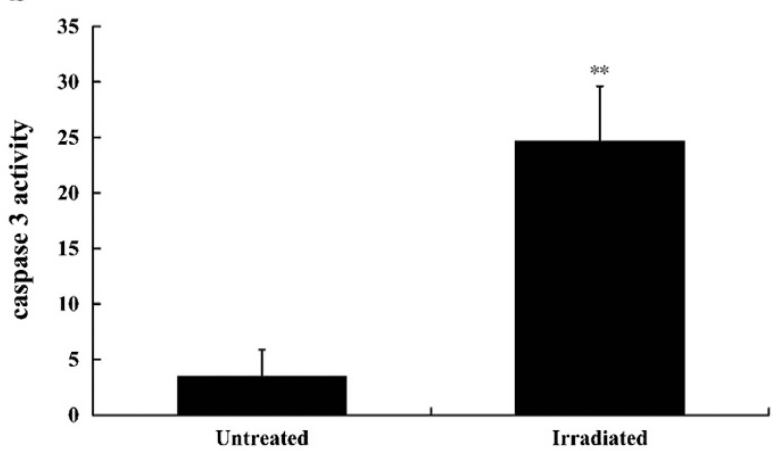

d

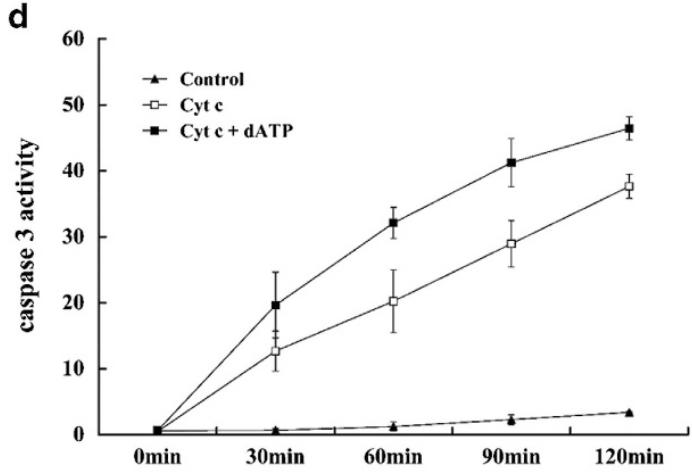

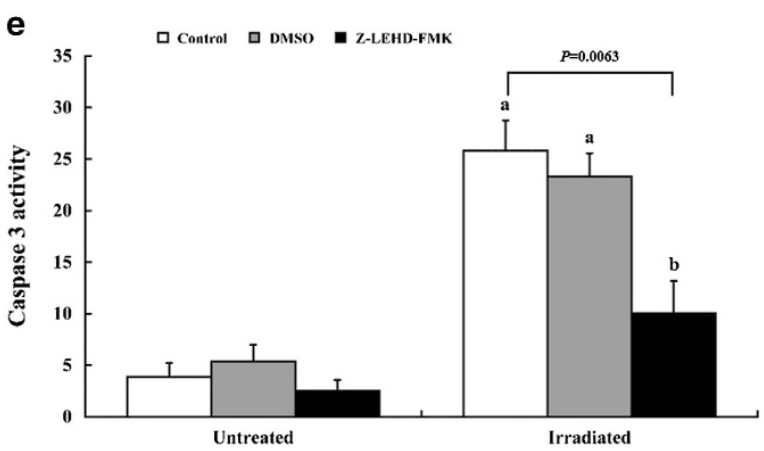

Figure 2 Determination of caspase 9 and caspase 3 involvement in mitochondrial apoptosis in C. gigas. (a) Caspase 9 and (b) Caspase 3 activity in oyster hemocytes was measured at $20 \mathrm{hpi}$. Non-irradiated cells were used as a negative control. Data are displayed as the mean \pm S.D. $(N=6) .{ }^{* *} P<0.01$. (c) Cytosolic extracts from oyster hemocytes were treated with cytochrome $c($ cyt $c)$, Z-LEHD-FMK, and dATP. Caspase 9 activity was measured at $2 \mathrm{~h}$ post cyt $c$ treatment $(10 \mu \mathrm{M}$ of horse cyt $c$ or oyster cyt $c)$. In Cg-cyt $c+Z$ LEHD-FMK group, the cytosolic extracts were preincubated with Z-LEHD-FMK $(35 \mu \mathrm{M})$ for $1 \mathrm{~h}$ and then treated with $\mathrm{Cg}$-cyt $c$. For Cg-cyt $c+d A T P$ treatment, the extracts were incubated with both $\mathrm{Cg}$-cyt $\mathrm{c}$ and dATP $(1 \mathrm{mM})$ for $2 \mathrm{~h}$ before activity assessment. Different letters indicate significant differences at $P<0.05$, whereas conditions annotated with the same letter were not significantly different. (d) Caspase 3 activity in oyster cytosolic extracts was monitored at different time points after treatment with $10 \mu \mathrm{M}$ oyster cyt $c$ with or without $1 \mathrm{mM}$ dATP. Untreated extract served as a negative control. (e) Caspase 3 activity was examined in irradiated and non-irradiated hemocytes pretreated with Z-LEHDFMK, DMSO vehicle, or left untreated at $20 \mathrm{hpi}$. Different small letters denote significant differences at $P<0.05$ while same letters denote not. All of the results in Figure 2 are shown as the mean \pm S.D. $(N=6)$

the addition of Cg-Cyt $c$. As expected, Cg-caspase 9 activity was substantially decreased significantly with the addition of Z-LEHD-FMK (Figure 2c). Moreover, irradiated hemocytes pretreated with Z-LEHD-FMK showed a markedly lower activity for both Cg-caspase 3 and Cg-caspase 9 (Figure 2e), demonstrating that the functions of these caspases in $C$. gigas were comparable to their vertebrate counterparts.

Identification and expression analysis of $\mathrm{Bcl}-2$ relatives in the Pacific oyster. B-cell lymphoma (Bcl)-2 protein family members are known regulators of mitochondrial apoptosis.
We identified seven candidate Bcl-2 homologs in the Pacific oyster by querying the annotated genome database, but none belonged to the pro-apoptotic 'BH3-only' subfamily. Nevertheless, we performed rapid-amplification of cDNA ends or PCR to amplify the entire coding sequence and subsequently validated their genetic sequences.

To study the functional significance of oyster Bcl-2 family members, we selected four candidate genes out of the seven, as they were more closely related to human Bcl-2 family members with regard to the domain architecture. We designated them as $\mathrm{Cg}-\mathrm{BCl}-2, \mathrm{Cg}-\mathrm{BCl}-\mathrm{xl}, \mathrm{Cg}-\mathrm{Bak}$, and $\mathrm{Cg}-\mathrm{Bax}$ 
based on their homology to human relatives. All of the four candidates contained $\mathrm{BH} 1, \mathrm{BH} 2$, and $\mathrm{BH} 3$ domains, whereas only $\mathrm{Cg}-\mathrm{Bcl}-2$ had a $\mathrm{BH} 4$ domain (Figure $3 \mathrm{a}$ ). In addition, $\mathrm{Cg}$-Bak and $\mathrm{Cg}$-Bax harbored a transmembrane domain absent in $\mathrm{Cg}-\mathrm{Bcl}-2$ and $\mathrm{Cg}-\mathrm{Bcl}-\mathrm{xl}$ (Figure 3a). An amino-acid sequence-based phylogenetic analysis showed that $\mathrm{Cg}-\mathrm{Bcl}-2$ and $\mathrm{Cg}-\mathrm{Bcl}-\mathrm{xl}$ clustered into the anti-apoptotic protein category, whereas $\mathrm{Cg}$-Bak and $\mathrm{Cg}$-Bax classified as pro-apoptotic proteins (Figure 3b).

Quantitative PCR (qPCR) analysis was performed to investigate the expression pattern of oyster Bcl-2 family genes in different tissues and under various environmental stresses. All the four genes displayed relatively high expression in gill and hemolymph (Supplementary Figure S2). Moreover, infection with ostreid herpesvirus 1 (OsHV-1, a common virus that can cause mass mortality of oyster) or Vibrio alginolyticus, as well air exposure and heat shock, markedly altered the expressions of these $\mathrm{Bcl}-2$ relatives (Supplementary Figure S3, Supplementary Figure S4,Supplementary Figure S5, and Supplementary Figure S6).

C. gigas Bcl-2 family members regulate apoptosis signaling. We first examined the contributions of the Pacific oyster Bcl-2 candidate homologs in cell death in the yeast Saccharomyces cerevisiae, as Bax and Bak from human ${ }^{31}$ and Schistosoma mediterranea ${ }^{18}$ can trigger cell death in yeast according to previous reports. Significantly, we found that both $\mathrm{Cg}$-Bak and $\mathrm{Cg}$-Bax induced yeast cell death (Figure 4a); however, co-expression of either $\mathrm{Cg}-\mathrm{Bcl}-2$ or human $\mathrm{Bcl}-2$ rescued yeast from $\mathrm{Cg}$-Bak- or $\mathrm{Cg}$-Bax-induced lethality (Figure 4a).

To further determine the roles of oyster Bcl-2 family members in apoptosis, we overexpressed Cg-Bak or Cg-Bax in HEK293T cells. Interestingly, neither Cg-Bak or Cg-Bax altered caspase 3 activity in these cells, nor did $\mathrm{Cg}-\mathrm{Bcl}-\mathrm{xl}$ or $\mathrm{Cg}-\mathrm{Bcl}-2$ (data not shown). However, $\mathrm{H}_{2} \mathrm{O}_{2}$-induced oxidative stress effectively stimulated caspase 3 activity level in HEK293T cells, which was markedly increased in counterparts with $\mathrm{Cg}$-Bak or $\mathrm{Cg}$-Bax overexpression (Figures $4 \mathrm{~b}$ and c). In addition, the co-expression of $\mathrm{Cg}-\mathrm{Bcl}-2$ or $\mathrm{Cg}-\mathrm{Bcl}-\mathrm{xl}$ with $\mathrm{Cg}$-Bak or $\mathrm{Cg}$-Bax significantly attenuated the caspase 3 activity in $\mathrm{H}_{2} \mathrm{O}_{2}$-treated cells when compared with treated controls with $\mathrm{Cg}$-Bak or $\mathrm{Cg}$-Bax expression alone (Figures $4 \mathrm{~b}$ and $c)$.

We then analyzed the expression of the four Bcl-2 family genes following UV irradiation and found a remarkable induction of all four candidates (Figure $4 d$ ), indicative of their involvement in apoptosis regulation. We performed siRNA assays on $\mathrm{Cg}$-Bak and $\mathrm{Cg}$-Bax, which effectively suppressed their expression (Figures $4 \mathrm{e}$ and $\mathrm{f}$ ). Subsequently, we irradiated $\mathrm{Cg}$-Bak-silenced, $\mathrm{Cg}$-Bax-silenced, and scrambled siRNA-treated hemocytes and measured apoptosis at 3 and $24 \mathrm{hpi}$, which revealed that $\mathrm{Cg}$-Bak-silenced and $\mathrm{Cg}$-Baxsilenced hemocytes were both significantly more resistant to UV-induced apoptosis than their scrambled siRNA-treated counterparts at $24 \mathrm{hpi}$ (Figures $4 \mathrm{~g}$ and h).

$\mathrm{Cg}$-Bak and $\mathrm{Cg}$-Bax translocate to the mitochondria and induce cytochrome $c$ release during apoptosis. To understand how the pro-apoptotic oyster Bcl-2 family proteins regulate mitochondrial apoptosis, we studied the subcellular localization of $\mathrm{Cg}$-Bak and $\mathrm{Cg}$-Bax in HeLa cells. Fluorescence microscopy showed that both $\mathrm{Cg}-\mathrm{Bak}$ and $\mathrm{Cg}-\mathrm{Bax}$
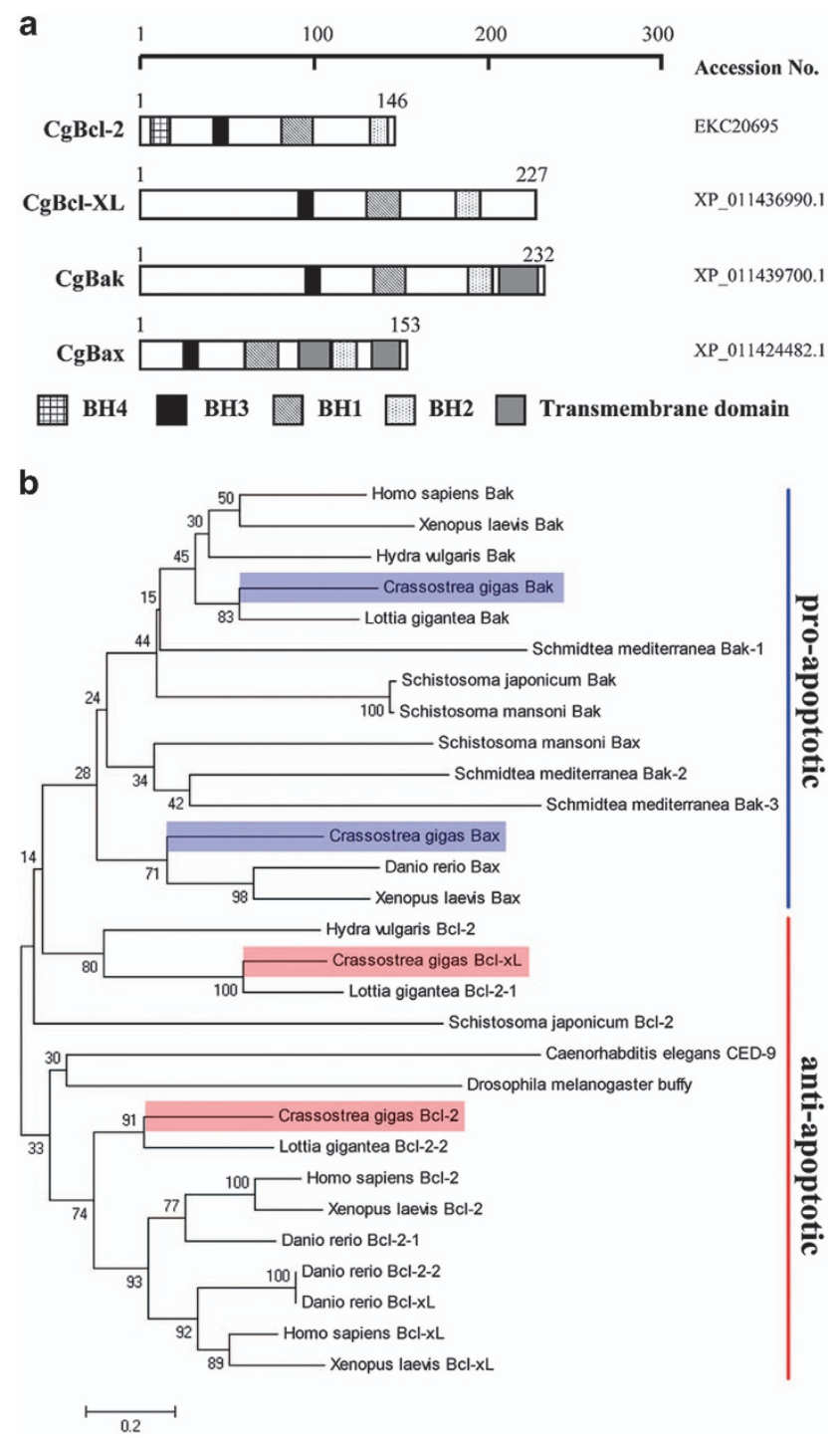

Figure 3 Sequence analysis of oyster Bcl-2 family proteins. (a) Small motif architecture of $\mathrm{Bcl}-2$ family proteins in Crassostrea gigas. C. gigas $\mathrm{Bcl}-2$ family proteins contained at least three of four conserved sequence motifs known as Bcl-2 homology domains (BH1-BH4, indicated in the figure). Cg-Bak and $\mathrm{Cg}$-Bax also contained the transmembrane domain (gray box). (b) Neighbor-joining phylogenetic tree of Bcl-2 family homologs from different vertebrate and invertebrate species. The neighbor-joining tree constructed by the MEGA program was based on the sequences of four $\mathrm{BCl}-2$ family proteins in C. gigas, along with $\mathrm{Bcl}-2$ family homologs from other species, including Bcl-2 homologs from Homo sapiens (NP_000624.2), Xenopus laevis (NP_001139565.1), Danio rerio (NP_001025424.1 and NP_571882.1), Drosophila melanogaster (NP_523702.1), Caenorhabditis elegans (NP_499284.1), Lottia gigantea (XP_009061217.1 and XP_009067239.1), Schistosoma japonicum (CAX69465.1), and Hydra vulgaris (NP_001274311.1); Bcl-xL homologs from Homo sapiens (CAA80661.1), Xenopus laevis (NP_001082147.1), and Danio rerio (NP_571882.1), Bak homologs from Homo sapiens (NP_001179.1), Xenopus laevis (NP_001089587.1), Lottia gigantea (XP_009064284.1), Schistosoma japonicum (CAX70134.1), Schistosoma mansoni (CCD80772.1), Schmidtea mediterranea (AEX93474.1, AEX93475.1 and AEX93476.1), and Hydra vulgaris (NP_001296708.1), and Bax homologs from Xenopus laevis (NP_001079104.1), Danio rerio (NP_571637.1), and Schistosoma mansoni (CCD81694.1) 
mainly localized throughout the cytoplasm of normal cells, but translocated to the mitochondria in a subset of cells following UV irradiation. (Figures $5 \mathrm{a}$ and b). These data were also validated in subcellular fractionation experiments in HEK293T cells with Cg-Bak and Cg-Bax overexpression (Figure 5c).

To ascertain whether the mitochondrial translocation of $\mathrm{Cg}$-Bak and $\mathrm{Cg}$-Bax was associated with their regulatory roles in apoptosis, we examined the impact of purified Cg-Bak and $\mathrm{Cg}$-Bax protein on isolated oyster mitochondria. When control mitochondria were incubated in storage buffer and centrifuged, cytochrome $c$ could only be detected in the precipitate; however, incubation with $\mathrm{CaCl}_{2}$ resulted in detectable cytochrome $c$ only in the supernatant (Figure $5 d$ ). Subsequent analyses showed that cytochrome $c$ was detectable in both the supernatant and precipitate when mitochondria were incubated with recombinant $\mathrm{Cg}$-Bak or $\mathrm{Cg}$-Bax (Figure $5 \mathrm{~d}$ ).

\section{Anti-apoptotic Bcl-2 family proteins directly bind $\mathrm{Cg}-\mathrm{Bak}$} and Cg-Bax. In mammals, anti-apoptotic Bcl-2 subfamily members interact with their pro-apoptotic counterparts, thereby inhibiting the activities of the latter. ${ }^{32}$ Thus, we used a yeast two-hybrid system to determine whether this regulatory interaction also occurred with $C$. gigas homologs. Notably, both $\mathrm{Cg}-\mathrm{Bcl}-2$ and $\mathrm{Cg}-\mathrm{Bcl}-\mathrm{xl}$ were found to interact with pro-apoptotic $\mathrm{Cg}$-Bak and $\mathrm{Cg}$-Bax (Figure 6a). A series of truncated mutants were constructed to identify the domain essential for mediating these interactions (Figure 6b). Results of yeast two-hybrid assays with the truncated mutants indicated that the $\mathrm{BH} 3$ domain facilitated the interactions between oyster Bcl-2 family members (Figure 6c), which was subsequently confirmed with co-immunoprecipitation (co-IP) assays. (Figures $6 \mathrm{~d}$ and e).

C. gigas $\mathbf{C g}-\mathrm{p} 53$ is involved in mitochondrial apoptosis. Despite the application of high-throughput sequencing technologies, a $\mathrm{BH} 3$-only homolog is yet to be discovered in mollusk. ${ }^{21,33,34}$ This absence led us to identify other regulators of mitochondrial apoptosis upstream of the Bcl-2 homologs. We first considered the oyster p53 homolog Cgp53 as a candidate, as p53 is known to regulate Bcl-2 family activities in mammals. ${ }^{35}$ Our preliminary analysis of $\mathrm{Cg}-\mathrm{p53}$ expression in oyster hemocyte showed a substantial upregulation in response to UV irradiation (Figure 7a). We then treated the hemocytes with the p53 inhibitor pifithrin-a and validated its effect of PFT- $a$ on $\mathrm{Cg}$-p53 expression (Figure 7b). Moreover, analysis of UV irradiation-induced apoptosis in PFT-a-treated hemocytes revealed that p53 inhibition substantially increased their apoptotic resistance at $3 \mathrm{hpi}$ and $6 \mathrm{hpi}$, but not at $24 \mathrm{hpi}$, when compared with untreated controls (Figure 7c). This is consistent with an increase of $\mathrm{Cg}-\mathrm{Bcl}-2$ and $\mathrm{Cg}-\mathrm{Bcl}-\mathrm{xl}$ levels (Supplementary Figure S7) together with the delay in $\mathrm{Cg}$-Bak activation, thus suggesting that the absence of p53 could promote apoptosis resistance through $\mathrm{Cg}-\mathrm{Bcl}-2$ and $\mathrm{Cg}-\mathrm{Bcl}-\mathrm{xl}$.

Cg-p53 regulates the $\mathrm{Bcl}-2$ family in mitochondrial apoptosis pathway of Pacific oyster. Dual-luciferase reporter assays were used to monitor $\mathrm{Cg}$-p53 transcriptional activity. The $\sim 2 \mathrm{~kb}$ region upstream of the $\mathrm{Cg}$-Bak, $\mathrm{Cg}$-Bax,
$\mathrm{Cg}-\mathrm{BCl}-2$, and $\mathrm{Cg}-\mathrm{BCl}-\mathrm{xl}$ start codons were considered as potential promoter regions and used to construct the $\mathrm{Cg}$-BakLuc, Cg-Bax-Luc, Cg-Bcl-2-Luc, and Cg-BCl-xl-Luc plasmids (Figure 8a). In preliminary experiments with HEK293T cells, $\mathrm{Cg}-\mathrm{p} 53$ elicited the transcription from $\mathrm{Cg}$-Bak-Luc and $\mathrm{Cg}$ $B a x-L u c$ promoters, whereas it repressed the transcription from $C g-B C l-2-L u c$ and $C g-B C l-x l-L u c$ promoters, all in a dose-dependent manner (Figures 8b-e).

To determine whether $\mathrm{Cg}$-p53 could regulate $\mathrm{Cg}$-Bak and $\mathrm{Cg}$-Bax in oyster cells, the expression patterns of $\mathrm{Cg}$-Bak and $\mathrm{Cg}$-Bax in PFT- $a$ treated hemocytes after UV light irradiation were determined. The qPCR data showed that PFT- $a$ treatment significantly delayed the activation of $\mathrm{Cg}$-Bak expression upon irradiation, compared with that in untreated hemocytes (Figure 8f), indicating that $\mathrm{Cg}$-p53 transactivates $\mathrm{Cg}$-Bak in C. gigas. For $\mathrm{Cg}$-Bax, however, the timing of activation is mostly unchanged in both PFT- $a$-treated and nontreated hemocytes (Figure $8 \mathrm{~g}$ ).

Considering that mammalian p53 regulates the activities of both anti-apoptotic and pro-apoptotic $\mathrm{Bcl}-2$ family proteins through a transcription-independent way (protein-protein interaction), $\mathrm{Cg}$-p53 may also bind to oyster Bcl-2 family members. This could serve as a plausible explanation for the unexpected absence of $\mathrm{Cg}$-Bax promoter activity in PFT- $a$ treated irradiated hemocytes. Thus, we performed a co-IP assay on $\mathrm{Cg}$-p53 in HEK293T cells with the four Bcl-2 family proteins of $C$. gigas, yielding positive results; hence, probable interactions exist between the proteins in question (Figure 8h).

\section{Discussion}

The mechanisms of invertebrate mitochondrial apoptosis are unclear. Current evidence demonstrates that neither MOMP and cytochrome $c$ release regulate mitochondrial apoptosis in Drosophila melanogaster and $C$. elegans; however, these events are essential for that in Schmidtea mediterranea. ${ }^{36-39}$ Therefore, further analysis should be carried out in other invertebrate species to elucidate the evolutionary physiology of mitochondrial apoptosis in invertebrates. Herein, we demonstrated the existence of MOMP and cytochrome $c$ release in mitochondrial apoptosis of $C$. gigas. These results confirmed previous speculation that MOMP and cytochrome $c$ release emerged prior to that of deuterostomes, but somehow missed in ecdysozoa species - at least with respect to Drosophila melanogaster and C. elegans. ${ }^{20}$

Caspase 9 and caspase 3 are proteases with vital roles in mitochondrial apoptosis. In this study, we found that both $\mathrm{Cg}$ caspase 9 and $\mathrm{Cg}$-caspase 3 were involved in mitochondrial apoptosis in $C$. gigas, with $\mathrm{Cg}$-caspase 9 likely acting as an upstream activator of $\mathrm{Cg}$-caspase 3 - consistent with their roles in vertebrates. ${ }^{40}$ However, the oyster APAF-1 homolog lacks the caspase recruitment domain (CARD domain) and only possesses the cytochrome $c$-interacting WD domain. In fact, no CARD domain-containing APAF-1 homolog has been identified in the Mollusca phylum to date, supporting the existence of a distinct mechanism of caspase 9 activation. Interestingly, the $C$. elegans APAF-1 homolog contains a CARD domain, but no WD domain, ${ }^{41}$ indicative of pathway diversity throughout invertebrates. 
$\mathrm{Bcl}-2$ family proteins are central regulators of mitochondrial apoptosis. In this study, we identified the existence of oyster $\mathrm{Bcl}-2$ family genes and demonstrated their regulatory roles in apoptosis. Notably, both Cg-Bak and Cg-Bax exhibited proapoptotic effects in yeast, consistent with that previously observed with their human ${ }^{31}$ and $S$. mediterranea homologs. ${ }^{18}$ The present work sought to define the functional significance of $\mathrm{Cg}$-Bak and $\mathrm{Cg}$-Bax in mitochondrial apoptosis, and revealed that both factors translocate from the cytoplasm to mitochondria in mammalian cells in response to UV irradiation. This result indicates that while $\mathrm{Cg}$-Bax likely functions in a similar manner to its mammalian counterpart, ${ }^{42,43} \mathrm{Cg}$-Bak may utilize an independent mechanisms as mammalian Bak mainly localizes to the mitochondrial outer a

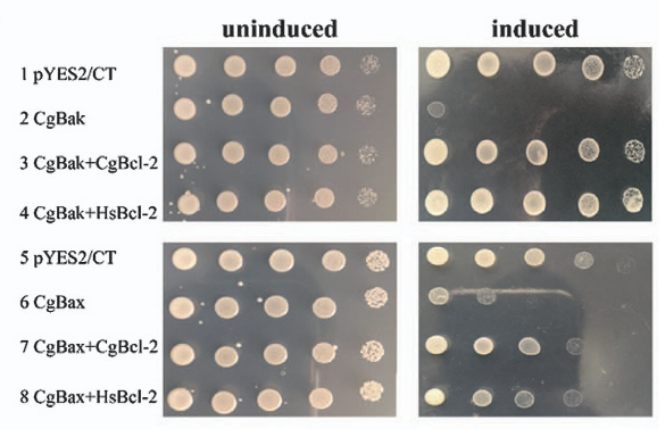

C
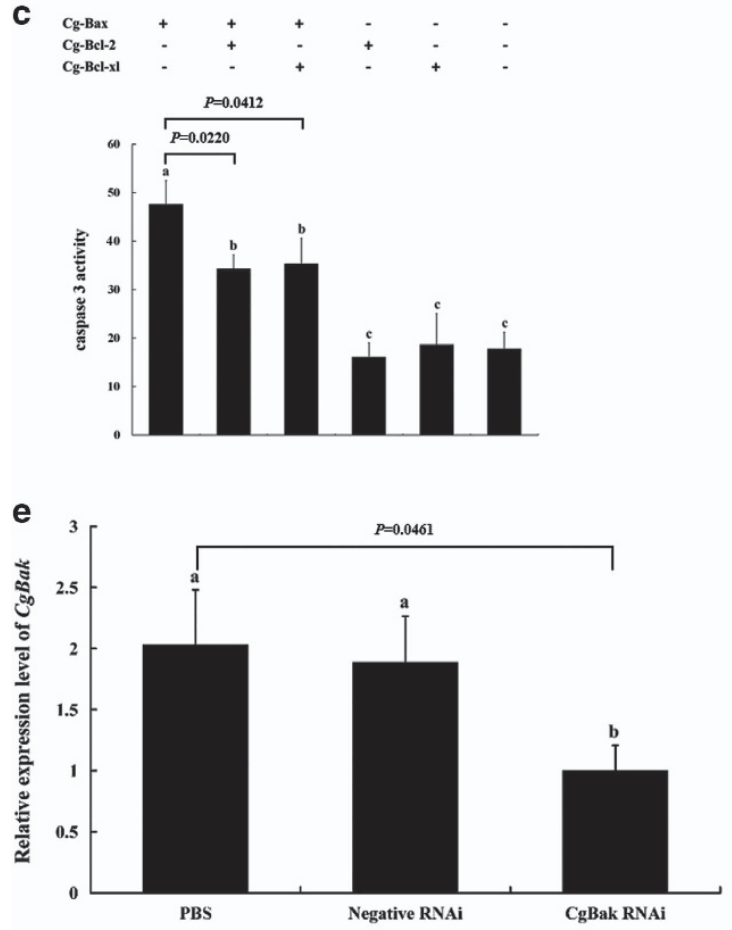

g

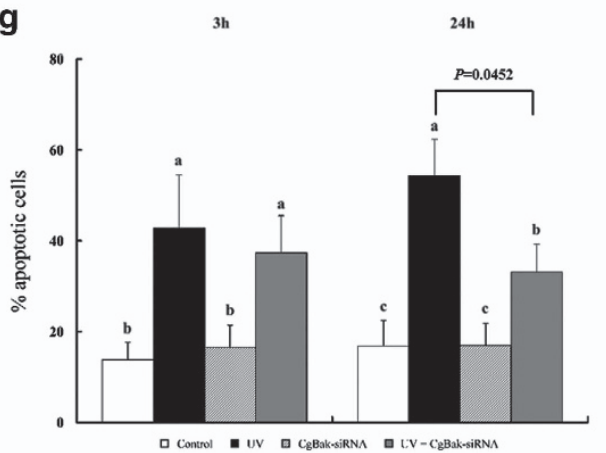

b

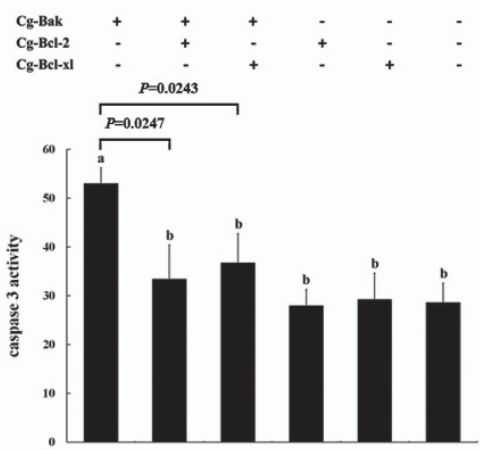

d
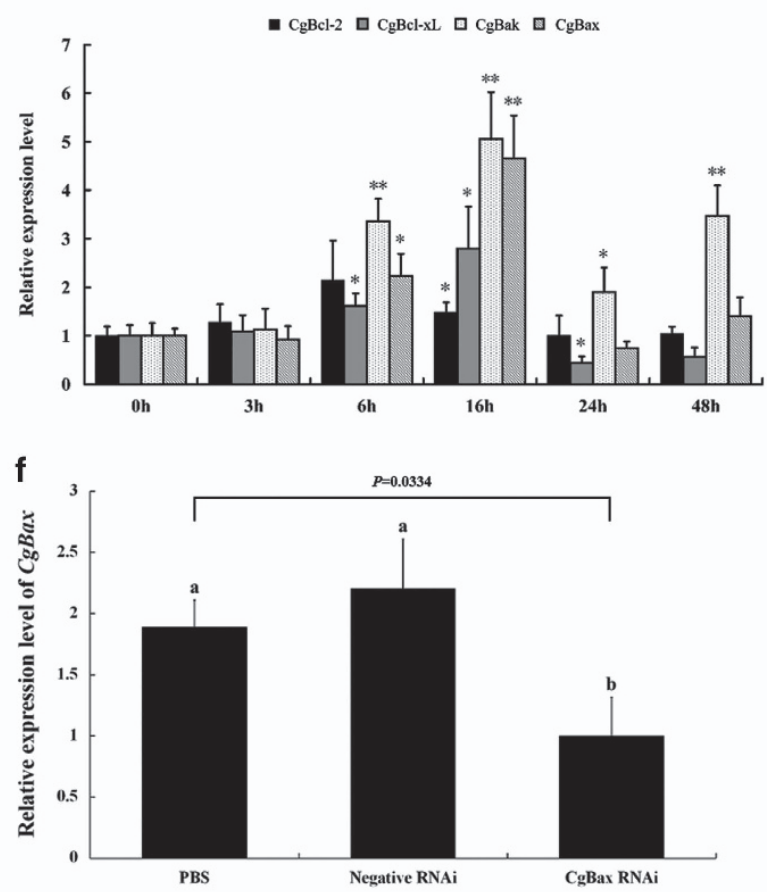

h

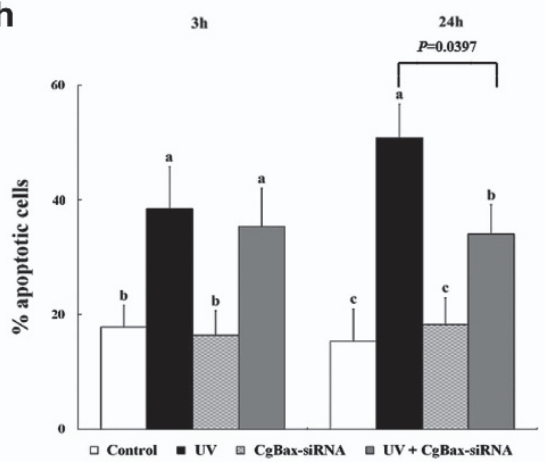


membrane in healthy cells. ${ }^{44}$ However, the inconsistencies in Cg-Bak and mammalian Bak subcellular localization might be the result of structural differences or the misfolding of $\mathrm{Cg}$-Bak in mammalian cells. We were unable to examine the distribution of these proteins in oyster cells due to the lack of suitable antibodies. Despite this, the result herein could still imply the association of the proteins with mitochondria during apoptosis. In fact, our previous study demonstrates a potential interaction between $\mathrm{Cg}$-Bak and the mitochondrial outer membrane porin Cg-VDAC2. ${ }^{45}$ Nevertheless, our results support that $\mathrm{Cg}$-Bak and $\mathrm{Cg}$-Bax induce cytochrome $c$ release, as observed with mammalian Bak and Bax. Moreover, our study also revealed that the interaction of antiapoptotic proteins ( $\mathrm{Cg}-\mathrm{Bcl}-2$ and $\mathrm{Cg}-\mathrm{Bcl}-\mathrm{xl})$ and pro-apoptotic proteins ( $\mathrm{Cg}$-Bak and $\mathrm{Cg}$-Bax) in $C$. gigas was mediated by the $\mathrm{BH} 3$ domain, consistent with vertebrates. ${ }^{46,47}$ In addition, whereas $\mathrm{Cg}$-Bak was found to be transcriptional activated by Cg-p53, Cg-Bax seemed to be more loosely regulated, although its promoter could be activated by $\mathrm{Cg}-\mathrm{p} 53$ in mammalian cells. This might not result from the regulation by $\mathrm{Cg}-\mathrm{BCl}-2$ or $\mathrm{Cg}-\mathrm{BCl}-\mathrm{xl}$, as the anti-apoptotic Bcl-2 family members were both negatively regulated by $\mathrm{Cg}-\mathrm{p} 53$. Therefore, it will be an interesting work to clarify the mechanisms regulating $\mathrm{Cg}$-Bax. Collectively, the apoptotic functions of the oyster Bcl-2 family proteins investigated here are fairly conserved with vertebrate counterparts, as was the transcriptional activity of $\mathrm{Cg}-\mathrm{p} 53 .{ }^{48}$

Significantly, we failed to discover a BH3-only homolog in C. gigas, nor has one been identified in the entire Mollusca phylum. ${ }^{33,34} \mathrm{BH}$-only proteins participate in the apoptotic response to various stressors. ${ }^{46}$ As such, the absence of a $\mathrm{BH} 3-o n l y$ homolog may imply a less-complex regulatory a
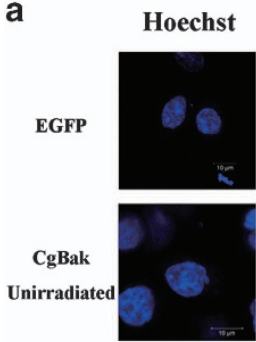

CgBak irradiated
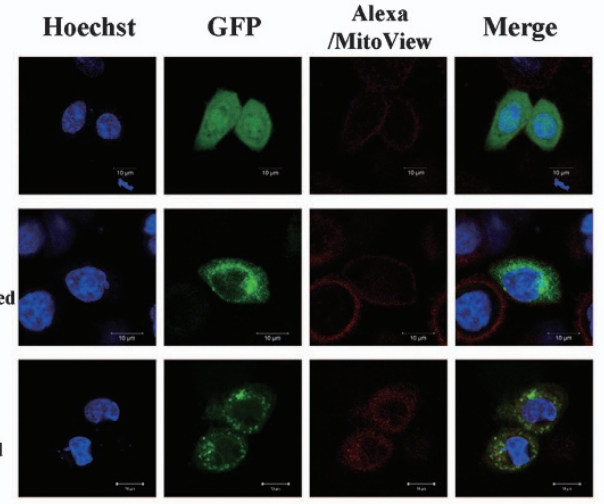

C

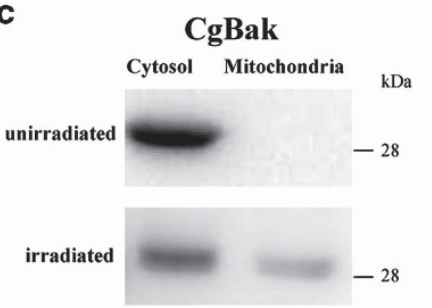

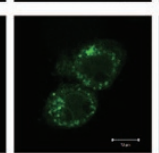

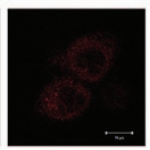

CgBax

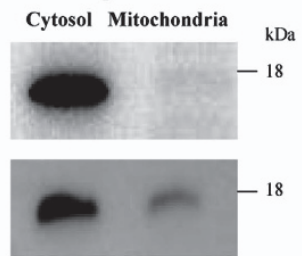

b
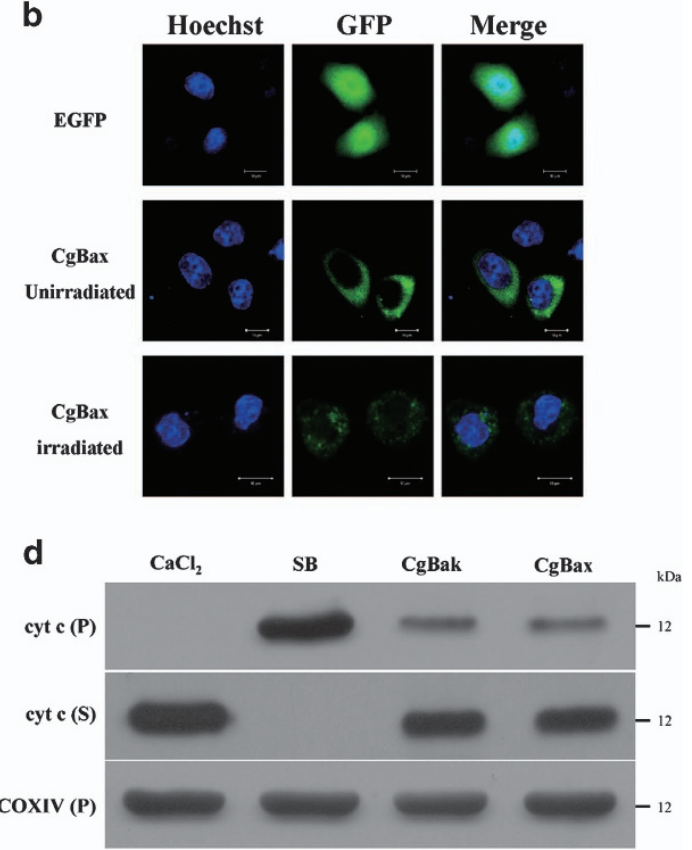

Figure 5 Investigation on the apoptotic regulatory functions of $\mathrm{Cg}$-Bak and $\mathrm{Cg}$-Bax. (a) HeLa cells were transfected with Cg-Bak-EGFP or pEGFP-N1 empty vector and UVirradiated or left untreated. Cell nuclei were stained with Hoechst 33342 (blue) and Alexa Fluor 633 (red) or MitoView 633 (red) to stain the cell membrane or mitochondria, respectively, as indicated in the figure. The green fluorescent signal indicated the distribution of overexpressed proteins. (b) HeLa cells were transfected with Cg-Bax-EGFP or pEGFP-N1 empty vector (green) and then UV-irradiated or left untreated. Cell nuclei were stained with Hoechst 33342 (blue). (c) Cg-Bak-EGFP and Cg-Bax-EGFP were overexpressed in HEK293T cells, which were then subjected to UV irradiation. Cytosolic and mitochondrial extracts from non-irradiated and irradiated cells were examined by western blot with anti-GFP antibody. (d) Isolated mitochondria from oyster cells were incubated with storage buffer, $\mathrm{CaCl}_{2}(300 \mu \mathrm{M})$, recombinant $\mathrm{Cg}-\mathrm{Bak}$ protein $(8 \mu \mathrm{M})$, or recombinant $\mathrm{Cg}-\mathrm{Bax}(8 \mu \mathrm{M})$ at room temperature for 30 min prior to centrifugation. The distributions of cytochrome $c$ in the supernatant $(\mathrm{S})$ and precipitate $(\mathrm{P})$ were then analyzed by western blot

Figure 4 Functional analysis of oyster Bcl-2 family proteins. (a) Plasmids expressing the indicated oyster or human Bcl-2 family proteins were transformed into Saccharomyces cerevisiae to determine their effect on yeast cell growth. Yeast were plated in 10-fold serial dilutions and induced to express the transformed genes. (b, $\mathbf{c}$ ) HEK293T cells transfected with various plasmids (indicated in the figure) were treated with $146 \mu \mathrm{M} \mathrm{H}_{2} \mathrm{O}_{2}$ for 40 min. Caspase 3 activity was examined 20 hpi by spectrophotometric detection of the chromophore p-nitroaniline (pNA) after cleavage from the labeled substrate DEVD-pNA. Data are shown as the mean \pm S.D. ( $N=3$ ). Different small letters indicate significant differences $(P<0.05)$, whereas the same letter indicated not. (d) Expression patterns of oyster Bcl-2 family genes following irradiation were detected. Data are displayed as the mean \pm S.D. $(N=3)$. ${ }^{*} P<0.05,{ }^{* *} P<0.01$. (e, f) Analysis of $C g$-Bak and $C g$-Bax mRNA levels in oyster hemocytes after siRNA transfection was used to confirm the RNAi knockdown. PBS-treated hemocytes were used as a negative control. Hemocytes in the negative RNAi group were treated with siRNA sequences as indicated in Method section. Data are displayed as the mean \pm S.D. $(N=3)$. Different small letters denote significant differences $(P<0.05)$ and the same letter denote not. $(\mathbf{g}$, h) SiRNA Cg-Bak-treated and Cg-Bax-treated hemocytes were UV-irradiated and apoptosis levels were measured at 3 hpi and 24 hpi. Data are shown as the mean \pm S.D. $(N=6)$. Different small letters referred to differences at $P<0.05$ 
a

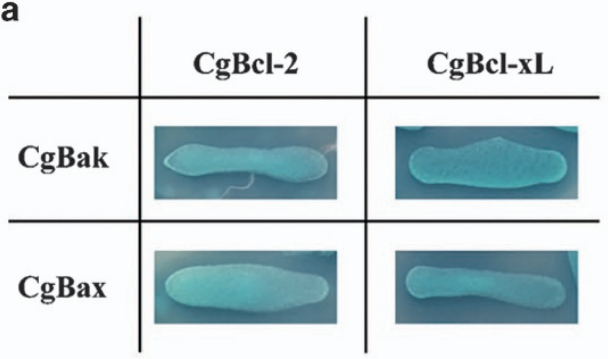

b
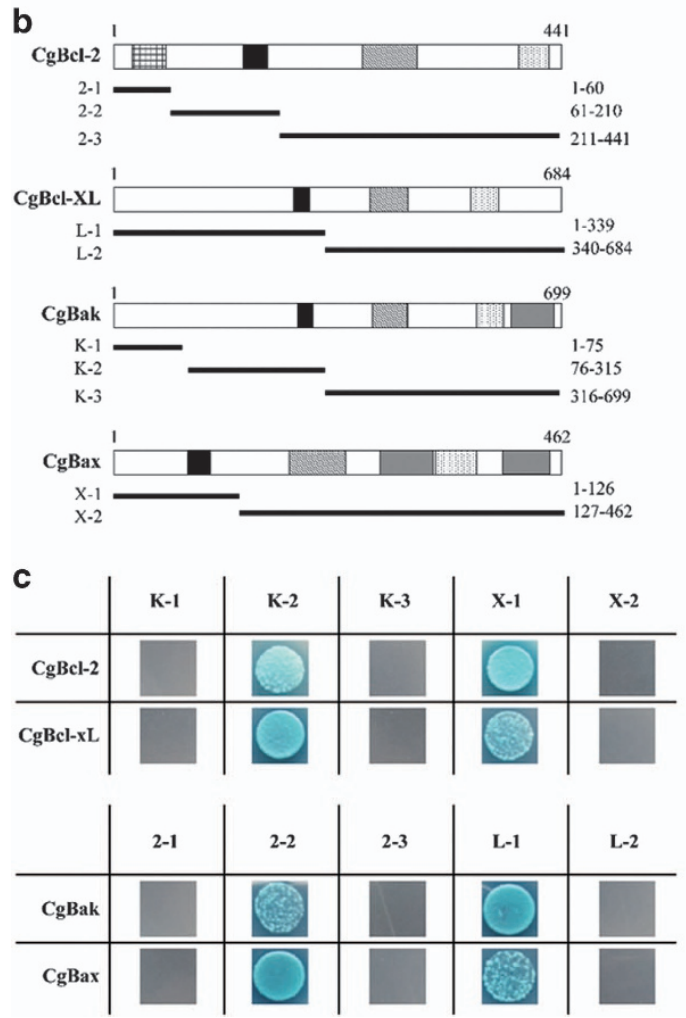

d
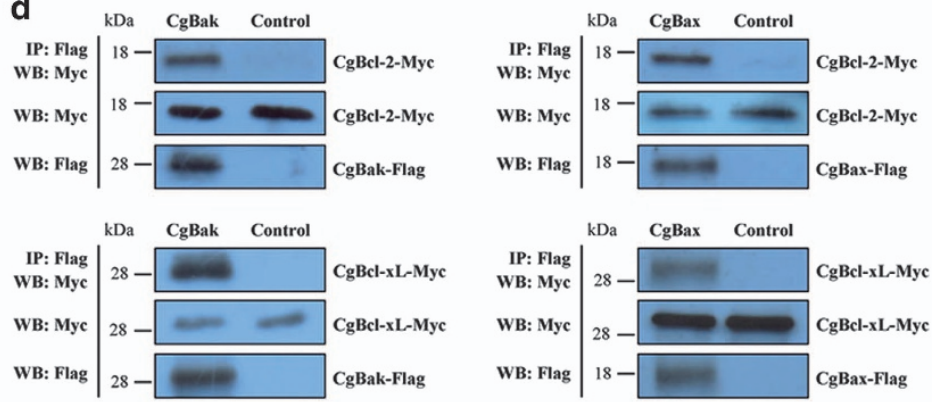

e

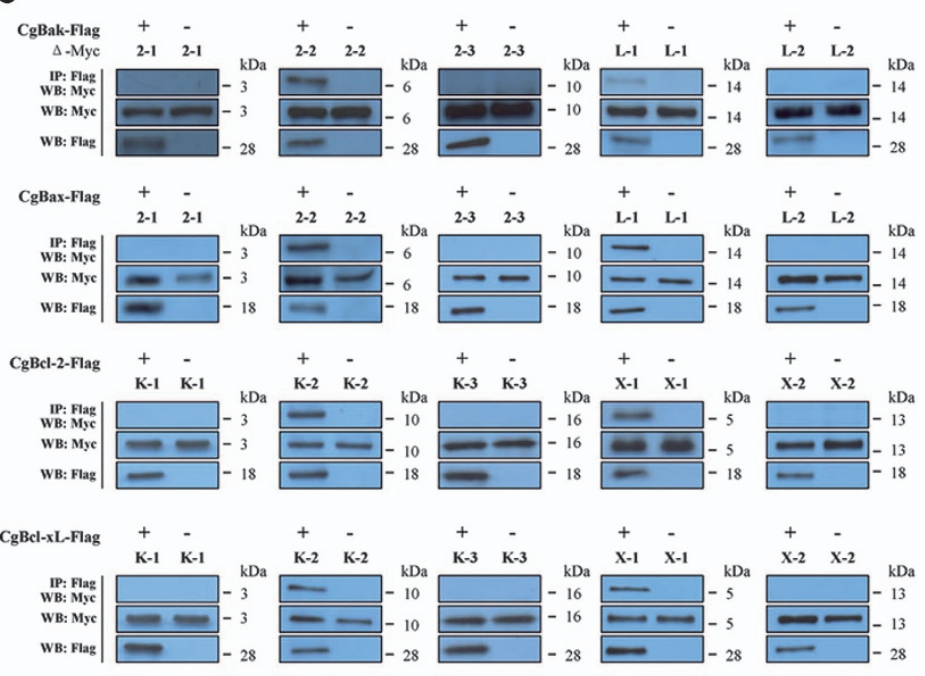

Figure 6 Interactions of oyster Bcl-2 anti-apoptotic and pro-apoptotic subfamily proteins. (a) Hybridized yeast containing both tested proteins was cultured on Quadruple drop-out (QDO) plates and imaged 3-5 days later. Blue colonies indicate a potential direct interaction. (b) Names and structures of the truncated mutant proteins used in this study. The BH1 (diagonal), BH2 (dots), BH3 (solid black), BH4 (grid), and transmembrane (solid gray) domains are shown. Numbers denote the nucleic acid location. (c) Interaction between distinct truncated mutant proteins and oyster Bcl-2 family proteins detected by yeast two-hybrid system. (d) Tested proteins carrying either FLAG- or Myc tags were co-overexpressed in HEK293T cells and interactions determined by co-immunoprecipitation assays using M2 anti-FLAG antibody. (Top) anti-Myc pulldown, (Middle) western blot using anti-Myc antibody, and (Bottom) western blot using anti-FLAG antibody. (e) Interaction between distinct truncated mutant proteins and oyster Bcl-2 family proteins detected by co-IP assays

network in $C$. gigas, or in all Mollusca species. A simpler network might expedite the process of apoptosis, particularly in species that lack adaptive immunity ${ }^{49}$ and extrinsic apoptosis. ${ }^{50}$ Alternatively, it might also indicate a less stable apoptotic regulatory system. Either way, the impact of missing BH3-only proteins on apoptosis and the environmental adaptation mechanism of $C$. gigas and mollusks is of future interest.

Apoptosis is a crucial host defense mechanism. ${ }^{51}$ Our confirmation of mitochondrial apoptosis in $C$. gigas and the regulatory functions of oyster Bcl-2 family members, along with the stimulus-induced expression differences of the oyster $\mathrm{Bcl}-2$ family genes under various stresses, support the extensive involvement of mitochondrial apoptosis in the environmental adaptation process of $C$. gigas. However, much effort will be needed to clarify the exact role of mitochondrial apoptosis in the response to various stressors.

In conclusion, the present study characterized the conservation and divergence of mitochondrial apoptosis in the Pacific oyster $C$. gigas. However, it is important to point out that many functional experiments were conducted in yeast or human cell lines as molecular tools in this study given the limitation of our experimental system. The limitation that is general to many non-model organisms is that cell lines and cell line-based research such as gene overexpression, proteinprotein interaction is still challenging. However, despite these 
a

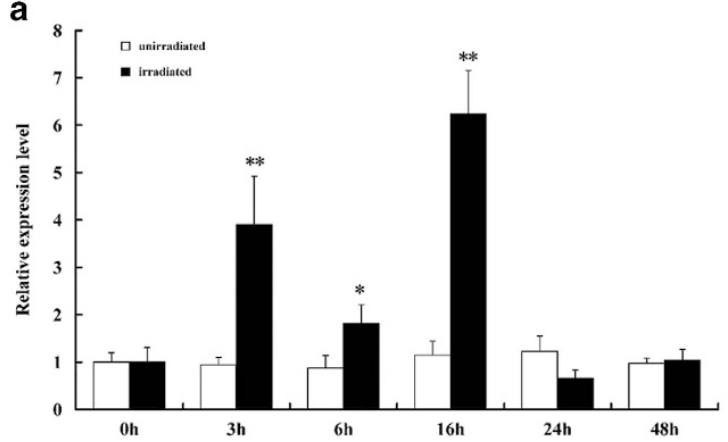

C

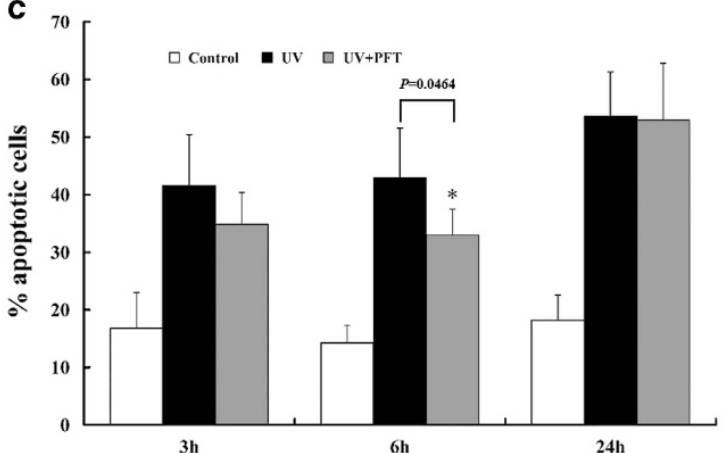

b

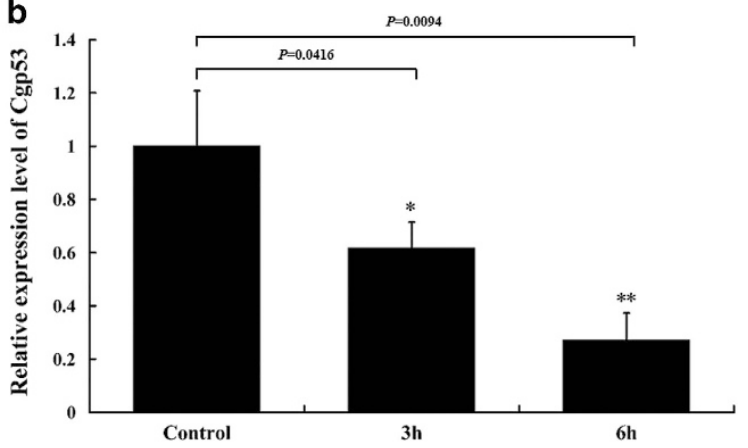

Figure 7 Involvement of $\mathrm{Cg}$-p53 in mitochondrial apoptosis in C. gigas. (a) Expression pattern of Cg-p53 in oyster hemocytes upon UV light irradiation. (b) Effect of PFT- $\alpha$ treatment on Cg-p53 expression. Oyster hemocytes were incubated with $100 \mu \mathrm{M} \mathrm{PFT}-\alpha$ for $1 \mathrm{~h}$ and $C g-p 53$ expression was analyzed $3 \mathrm{~h}$ and $6 \mathrm{~h}$ later. The data in (a) and (b) are shown as the mean \pm S.D. $(N=3)$. (c) Apoptosis was monitored by annexin V/PI immunostaining in hemocytes following treatment as indicated. Data are displayed as the mean \pm S.D. $(N=6) .{ }^{*} P<0.05,{ }^{*} P<0.01$

limitations, we found most events in $C$. gigas mitochondrial apoptosis displayed great similarity to that in vertebrate and $S$. mediterranea including MOMP and cytochrome c release. On the other hand, the absence of $\mathrm{BH}$-only proteins and the lack of a domain-intact APAF-1 homolog in Pacific oyster were indicative of pathway diversity in invertebrates. Continued investigation in other invertebrates will aid in our understanding of mitochondrial apoptosis pathway evolution.

\section{Materials and Methods}

Chemicals, plasmids, small-interfering RNAs, and antibodies. $\mathrm{H}_{2} \mathrm{O}_{2}$ was purchased from Sangon (Shanghai, China). Cytochrome $\mathrm{c}$ from equine heart was purchased from Solarbio (Beijing, China), and C. gigas cytochrome $\mathrm{c}$ was synthesized by Chemgen Biotechnology (Shanghai, China). dATP was obtained from Tiangen (Beijing, China). The Z-LEHD-FMK and PFT- $\alpha$ inhibitors were purchased from BioVision (Milpitas, CA, USA) and Beyotime (Jiangsu, China), respectively. The pGADT7, pGBKT7, and pEGFP-N1 plasmids were purchased from Takara (Shiga, Japan). pCMV-N-Myc and pCMV-N-FLAG plasmids were obtained from Beyotime and the pYES2/CT from Invitrogen (Carlsbad, CA, USA). The pRL-TK and pGL3-basic plasmids were both from Promega (Madison, MI, USA). Small-interfering RNAs targeting Cg-Bak (Cg-Bak1 sense: 5'-GGACGUGA UCAGGAACUUUTT-3', anti-sense: 3'-AAAGUUCCUGAUCACGUCCTT-5'; CgBak2 sense: 5'-GGCGAUAUGCCGAUGAAUUTT-3', anti-sense: 3'-AAUUCAUCGGCAUA UCGCCTT-5'; CgBak3 sense: 5'-GGUCAUUGUCAGUCAUGUUTT-3', anti-sense: 3'-AACAUGACUGACAAUGACCTT-5'; scrambled negative control siRNA sense: 5'-UUCUCCGAACGUGUCACGUdTdT-3', anti-sense: 3'-ACGUGACACGUUCGGA GAAdTdT) and $\mathrm{Cg}$-Bax (Cg-Bax1 sense: 5'-GCAGAGCUUUACGUUGCAUTT-3', anti-sense: $3^{\prime}$-AUGCAACGUAAAGCUCUGCTT-5'; Cg-Bax2 sense: 5'-CCUUUGG AAGGCACUCAAATT-3', anti-sense: 3'-UUUGAGUGCCUUCCAAAGGTT-5'; Cg-Bax3 sense: 5'-GCAGAGUGGGAUGUCUAUUTT-3', anti-sense: 3'-AAUAGACAUCCCAC
UCUGCTT-5') were obtained from GenePharma (Shanghai, China). Antibodies against FLAG and EGFP were purchased from Sigma (St. Louis, MO, USA). Myc antibody was from Roche (Basel, Switzerland). Antibody against cytochrome $c$ was synthesized by Chemgen Biotechnology. Peroxidase-labeled mouse IgG secondary antibody was purchased from KPL (Gaithersburg, MD, USA).

Oyster and primary hemocyte culture. Pacific oysters averaging $7 \mathrm{~cm}$ in shell height were obtained from a local farmer in Qingdao, China, and acclimatized in tanks with $20 \pm 0.5^{\circ} \mathrm{C}, \mathrm{pH} 8 \pm 0.3$ seawater. Primary hemocyte culture was performed as previously described with slight modifications. ${ }^{52}$ In brief, hemocytes were withdrawn from the pericardial cavity using a sterile 21-gauge needle attached to a $1 \mathrm{ml}$ syringe containing $0.1-0.2 \mathrm{ml}$ ice-cold filtered sterile seawater (FSW) supplemented with $2 \mathrm{~g} / \mathrm{l}$ glucose. The cells were plated into 6 -well plates, adjusted to $\sim 2 \times 10^{6}$ per well, and allowed to adhere for $30 \mathrm{~min}$ at room temperature. Hemolymph then was removed and Leibovitz L-15 medium (Sigma) supplemented with additives ${ }^{52}$ (including $0.54 \mathrm{~g} / \mathrm{l} \mathrm{KCl}, 20.2 \mathrm{~g} / \mathrm{l} \mathrm{NaCl}, 0.6 \mathrm{~g} / \mathrm{l} \mathrm{CaCl}, 3.9 \mathrm{~g} / \mathrm{l} \mathrm{MgCl}$, $1 \mathrm{~g} / \mathrm{l} \mathrm{MgSO}, 20.8 \mathrm{~g} / \mathrm{l}$ glucose, $220 \mu \mathrm{g} / \mathrm{ml}$ streptomycin, $100 \mu \mathrm{g} / \mathrm{ml}$ gentamicin, $100 \mu \mathrm{g} / \mathrm{ml}$ penicillin, and $0.1 \mu \mathrm{g} / \mathrm{ml}$ amphotericin B) was added to suspend the cells before culturing at $18^{\circ} \mathrm{C}$

Viral challenge, vibrio challenge, heat shock, air exposure, and UV irradiation. Viruses were obtained as previously described. ${ }^{53}$ Live $V$. alginolyticus were suspended with sterilized PBS and adjusted to $5 \times 10^{7} \mathrm{cell} / \mathrm{s} / \mathrm{ml}$. Before challenge, a small hole was made, using a sand-saw, on the edge of the oysters' shells to accommodate the injection. Three days later, $0.1 \mathrm{ml}$ viral homogenate, the $V$, alginolyticus suspension or PBS was injected into the oysters. Six individuals from each challenge group were randomly sampled at $0,3,6,12,24$, 48 , and $72 \mathrm{~h}$ after injection and the hemocytes were collected. For heat shock treatment, oysters were placed in tanks with $35^{\circ} \mathrm{C}$ seawater for $1 \mathrm{~h}$, transferred back to $25 \pm 0.5^{\circ} \mathrm{C}$ seawater, and then, six individuals from each group (treated and untreated) were sampled $0,1,3,6,12$, and $24 \mathrm{~h}$ later. For air exposure experiment, oysters were placed in a tank without seawater at $20 \pm 1^{\circ} \mathrm{C}$ and then 
tissues were collected from six individuals in each group (treated and untreated) at $1,3,5,7,9,10$, and 11 days after exposure. For UV irradiation, cell culture medium was reduced to $500 \mu \mathrm{l}$ prior to irradiation. Hemocytes were then exposed to UV light ( $15 \mathrm{~W}$, Philips, Netherlands) for $20 \mathrm{~min}$, the media volume restored to $1 \mathrm{ml}$, and cells were sampled at distinct time points based on the analysis. Hemocytes from six independent wells were sampled as experimental replicates at each time point.

Transmission electron microscopy. TEM analysis of oyster hemocytes was performed following a previous study. ${ }^{29}$ Hemocyte suspensions $\left(1 \times 10^{6}\right.$ cells $)$ were centrifuged at $500 \times \mathrm{g}$ for $8 \mathrm{~min}$ at $4{ }^{\circ} \mathrm{C}$, and the supernatant was discarded. Samples were fixed in $3 \%$ glutaraldehyde solution for 1 day at $4{ }^{\circ} \mathrm{C}$. After 3 washes with $0.4 \mathrm{M}$ cacodylate buffer, the cells were post-fixed with a solution of $1 \%$ osmium tetroxide for $1 \mathrm{~h}$ at $4{ }^{\circ} \mathrm{C}$. Then, the cells were washed twice in $0.4 \mathrm{M}$ cacodylate buffer. After dehydration in successive baths of ethanol and two baths of propylene oxide, samples were progressively impregnated and embedded in Epon. After polymerization at $60^{\circ} \mathrm{C}$, semi-thin sections were cut to $1 \mathrm{~mm}$ thickness for quality control and then to 80-85 $\mathrm{nm}$ for examination on a Leica Ultracut (EM UC6), floated onto copper EM grids, and stained with uracil acetate/Fahmys lead citrate. The sections were examined using a transmission electron microscope $(\mathrm{H}-7000$, Hitachi, Japan).

Real-time PCR analysis. Total RNA from tissues and cells were extracted using TRIzol (Invitrogen) following the manufacturer's instructions. RNA integrity was assessed using agarose gel electrophoresis, and purity was estimating according to the A260/280 absorption ratio measured using a NanoDrop 2000 Spectrophotometer (Thermo Fisher Scientific, Sunnyvale, CA, USA). CDNA was synthesized by reverse transcription with the PrimeScript RT reagent kit with gDNA Eraser (TaKaRa, Shiga, Japan). Real-time PCR was carried out on an ABI 7500 Fast Real-Time PCR System (Applied Biosystems, Foster City, CA, USA) using $2 \times$ SYBR Ex Taq mix (TaKaRa) according to the manufacturer's protocol. Cg-GAPDH was used as an internal control for expression analysis in response to OsHV-1, heat shock and air exposure. ${ }^{23,45} \mathrm{Cg}-\beta$-actin was used as an internal control in UV light irradiation analyses. ${ }^{25}$

Mammal cell cultures and transfection. HEK293T cells (ATCC, Manassas, VA, USA) were cultured in high-glucose Dulbecco's Modified Eagle's Medium (HyClone, Logan, UT, USA). HeLa cells were cultured in modified Roswell Park Memorial Institute (RPMI)-1640 medium (HyClone). Both media were supplemented with $10 \%$ fetal bovine serum (HyClone), penicillin $(100 \mathrm{U} / \mathrm{ml})$, and streptomycin $(100 \mathrm{U} / \mathrm{ml})$. Cells were maintained at $37^{\circ} \mathrm{C}$ in a humidified atmosphere of $5 \% \mathrm{CO}_{2}$. Plasmid transient transfection was performed with Lipofectamine 3000 (Invitrogen) according to the manufacturer's protocol.

Yeast death assays. pYES2/CT constructs carrying distinct fragments with or without pADH with the indicated inserts were transformed into $S$. cerevisiae, which was then cultured on the appropriate non-inducing medium as previously described. ${ }^{18}$ Isolated colonies were suspended in water, diluted 10-fold, and then plated on inducing and non-inducing medium. Plates were imaged $\sim 3$ days later.

Yeast two-hybrid and co-IP assays. The yeast two-hybrid system was carried out using Clontech Matchmaker Gold Yeast Two-Hybrid System (TaKaRa). pGADT7 and pGBKT7 carrying various oyster gene fragments were transformed into the Y187 and Gold yeast strains, respectively. Y187 cells and Gold cells were cultured onto selective plates with synthetically defined medium (SD) lacking leucine (SD/-Leu) or tryptophan (SD/-Trp) separately. Three days later, positive yeast strains on SD/-Leu and SD/-Trp were collected and hybridized in $2 \times$ yeast extract peptone dextrose (YPDA) medium and selected on double drop-out SD/-Leu/-Trp medium.
The blue hybridized clones growing on quadruple drop-out SD/-Ade/-His/-Leu/-Trp medium supplemented with $\mathrm{X}-\alpha$-Gal and Aureobasidin A (TaKaRa) indicated potential protein interactions. For co-IP assays, HEK293T cells transfected with plasmids expressing the FLAG and Myc tags were harvested at $30 \mathrm{~h}$ posttransfection with cell lysis buffer (Beyotime). Input samples were prepared from the cell lysate. The remaining lysate was mixed with anti-FLAG M2 magnetic beads (Sigma-Aldrich) and shaken gently on a roller shaker for 1-2 h. Subsequently, the magnetic beads were washed three times with cell lysis buffer and incubated with $2 \times$ SDS-PAGE loading buffer (TaKaRa) for $8 \mathrm{~min}$ at $100^{\circ} \mathrm{C}$ to elute the bound protein. Then, the beads were removed and immunoprecipitated proteins were analyzed using western blotting.

Extraction of mitochondrial and cytoplasmic proteins and western blot analysis. Mammalian and oyster mitochondria were isolated using a Cell Mitochondria Isolation Kit (Beyotime) following the manufacturer's protocol. The mitochondrial or cytoplasmic proteins were extracted from the prepared fractions with lysis buffer. For western blotting, proteins were resolved by $12 \%$ SDS-PAGE and transferred onto a $0.45 \mathrm{~nm}$ pore nitrocellulose membrane with the use of Semi-dry blotter (GenScript, Jiangsu, China). The membrane was then blocked with TBST $(20 \mathrm{mmol} / / \mathrm{Tris}-\mathrm{HCL}, 150 \mathrm{mmol} / \mathrm{l} \mathrm{NaCl}$, and $0.05 \%$ Tween-20) containing $5 \%$ skimmed milk at room temperature for $1 \mathrm{~h}$, and then incubated with the appropriate antibodies at $4{ }^{\circ} \mathrm{C}$ overnight, washed three times with TBST, incubated with peroxidase-labeled secondary antibodies at room temperature for $1 \mathrm{~h}$, and finally washed five times with TBST. Western Lightning Plus-ECL substrate (PerkinElmer, Waltham, MA, USA) was then added to membranes, which were exposed to X-OMAT AR X-ray film (Eastman Kodak, Rochester, NY, USA).

Subcellular localization. pEGFP-N1 carrying distinct gene fragments were transfected into HeLa cells. HeLa cells were rinsed once with PBS $24 \mathrm{~h}$ later and then stained with $2 \mathrm{mg} / \mathrm{ml}$ Hoechst 33342 (Invitrogen) for $10 \mathrm{~min}$ at $37^{\circ} \mathrm{C}$. Subsequently, the cells were washed twice with PBS, stained with Alexa Fluor 594 (Life Technologies, Carlsbad, CA, USA) for $15 \mathrm{~min}$ at $37^{\circ} \mathrm{C}$, washed three times with PBS, and then cultured in modified RPMI-1640 medium without fetal bovine serum. The visualization of protein subcellular localization was performed by confocal microscopy (Carl Zeiss, Oberkochen, Germany).

Inhibitor treatments on oyster hemocytes. Cell culture medium was replaced with fresh medium containing one of the inhibitors: PFT- $\alpha(100 \mu \mathrm{M})$, Z-LEHD-FMK $(35 \mu \mathrm{M})$, or siRNA $(30 \mu \mathrm{g} / \mathrm{ml})$. Cells were incubated with PFT- $\alpha$ or Z-LEHD-FMK for $1 \mathrm{~h}$, or siRNA for $24 \mathrm{~h}$ before UV light irradiation.

Transcription activity assay. HEK293T cells were used to examine $\mathrm{Cg}-\mathrm{p5} 3$ transcriptional activity. The region $\sim 2 \mathrm{~kb}$ upstream of the $\mathrm{Cg}$-Bak, $\mathrm{Cg}-\mathrm{Bax}, \mathrm{Cg}-\mathrm{BCl}-2$, and $\mathrm{Cg}-\mathrm{BCl}-\mathrm{xl}$ start codons were considered as potential promoter regions and cloned to the pGL3-basic luciferase reporter plasmid to generate the Cg-Bak-Luc, $\mathrm{Cg}$-Bax-Luc, $\mathrm{Cg}$-BCl-2-Luc, and $\mathrm{Cg}$-BCl-xl-Luc plasmids. Cells were co-transfected with varying amounts of pRL-TK, luciferase reporter, pCMV-N-Myc-Cg-p53, and pCMV-N-Myc plasmids and luciferase activity was measured using Dual-Luciferase Reporter Assay System (Promega) $24 \mathrm{~h}$ after transfection.

Assessment of caspase activity and apoptosis. For caspase 3 and caspase 9 activity assays, HEK293T cells or oyster hemocytes were collected, lysed, and the concentration of total protein measured by Bradford method. Caspase activity was then monitored with the Caspase 3 Activity Assay Kit (Beyotime) and Caspase 9 Activity Assay Kit (Beyotime). Annexin V/PI immunostaining was used to assess apoptosis in cells using the FITC-Annexin V Apoptosis Detection Kit (BD Biosciences, San Jose, CA, USA) according to the

Figure 8 Role of $\mathrm{Cg}$-p53 on regulating Bcl-2 family activities in mitochondrial apoptosis pathway in C. gigas. (a) Schematic diagram showing the regions of $\mathrm{Cg}$-Bak, $\mathrm{Cg}$-Bax, $\mathrm{Cg}-\mathrm{BCl}-2$, and $\mathrm{Cg}-\mathrm{BCl}-\mathrm{xl}$ considered as presumed promoter regions (gray) and subcloned into the pGL3-basic plasmid to construct the luciferase reporter. (b) Transactivation activity of $\mathrm{Cg}$-p53 to $\mathrm{Cg}$-Bak. The luciferase reporter containing presumed promoter region of $\mathrm{Cg}$-Bak, pCMV-Cg-p53, and pRL-TK (as an internal control) were co-transfected into HEK293T cells and luciferase activity was measured $24 \mathrm{~h}$ later. Transactivation activity is expressed as fold increase over the control group (far left column) with no pCMV-Cg-p53. (c) Transactivation activity of $\mathrm{Cg}$-p53 to $\mathrm{Cg}$-Bax. (d) Transactivation activity of $\mathrm{Cg}$-p53 to $\mathrm{Cg}-\mathrm{BCl}-2$. (e) Transactivation activity of $\mathrm{Cg}-\mathrm{p} 53$ to $\mathrm{Cg}-\mathrm{BCl}-\mathrm{xl}$. (f) $\mathrm{Cg}$-Bak, and (g) $\mathrm{Cg}$-Bax expression in PFT- $\alpha$-treated hemocytes following irradiation. Data in $(\mathbf{b}-\mathbf{g})$ are shown as the mean \pm S.D. $(N=3) .{ }^{*} P<0.05,{ }^{* \star} P<0.01$. (h) Interactions between $\mathrm{Cg}-\mathrm{p} 53$ and the four oyster Bcl-2 family proteins determined by co-IP assays in HEK293T cells. (Top) The IP samples against anti-Myc antibody. (Middle) The input samples against anti-Myc antibody. (Bottom) The input samples against anti-FLAG antibody 
manufacturer's instructions. In brief, cells were washed with PBS, suspended with binding buffer, stained with FITC-Annexin $\mathrm{V}$ and PI, and analyzed with a FACS Calibur flow cytometer (BD).
JC-1 assay for MMP. The MMP of oyster hemocytes was evaluated with the JC-1 Mitochondrial Membrane Potential Detection Kit (Beyotime) according to the manufacturer's protocol. Briefly, hemocytes that mixed with $10 \mu \mathrm{M}$ CCCP for 20 min
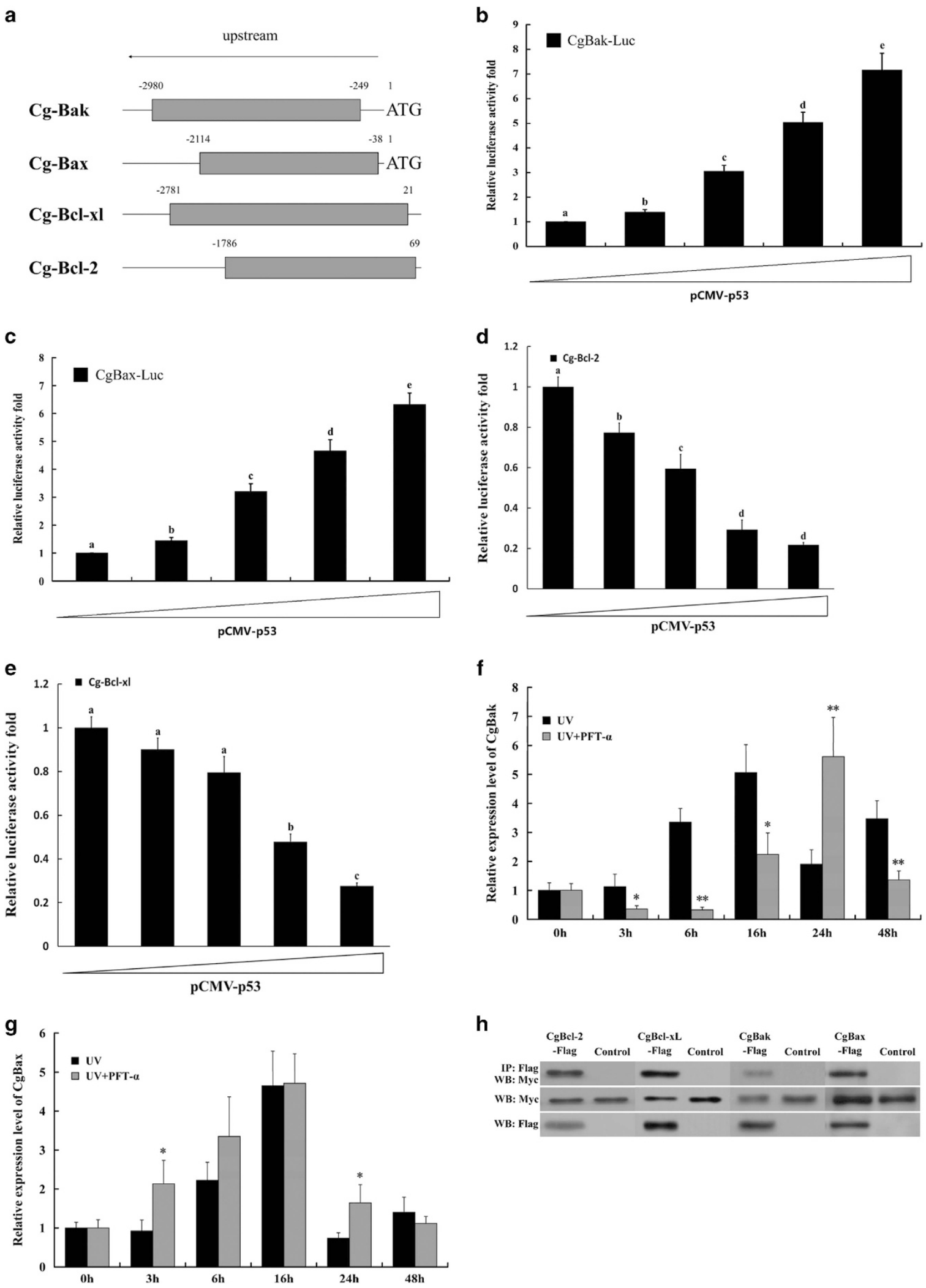

f

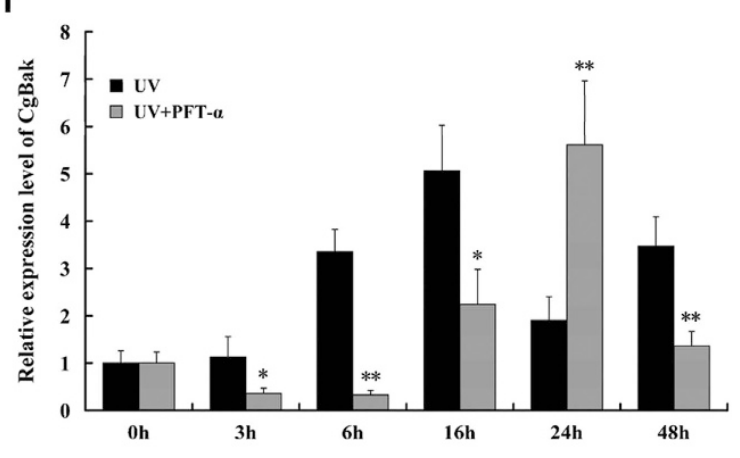

h

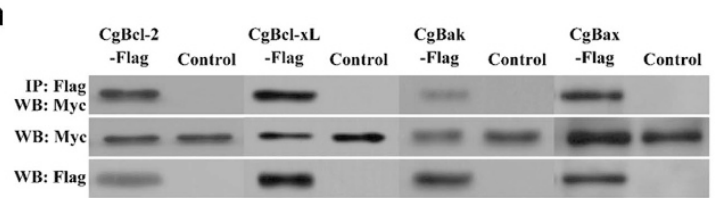


before JC-1 staining served as a positive control. Hemocytes in each well were collected and resuspended with $1 \mathrm{ml}$ modified L-15 medium and then mixed with JC-1 staining solution. Twenty minutes later, the cells were rinsed twice with $1 \times$ staining buffer and analyzed with a Varioskan Flash multimode reader (Thermo Fisher Scientific).

Statistical analysis. Data were analyzed by Student's $t$-test or one-way ANOVA to determine the differences among different groups. $P<0.05$ was considered statistically significant.

\section{Conflict of Interest}

The authors declare no conflict of interest.

Acknowledgements. This study was supported by the National Basic Research Program of China (973 Program, No. 2010CB126402), the National Natural Science Foundation of China (31302219), the National High Technology Research and Development Program (863 program, 2012AA10A405), the Earmarked Fund for Modern Agro-industry Technology Research System (CARS-48), and Taishan Scholars Climbing Program of Shandong. This research was supported by the National Natural Science Foundation of China (31530079), the Strategic Priority Research Program of 'Western Pacific Ocean System: Structure, Dynamics and Consequences' (Grant No. XDA11000000), Technological Innovation Project Financially Supported by Qingdao National Laboratory for Marine Science and Technology (2015ASKJ02-03) and the Earmarked Fund for Modern Agro-industry Technology Research System (CARS-48).

1. Guofan Z, Xiaodong F, Ximing G, Li L, Ruibang L, Fei X et al. The oyster genome reveals stress adaptation and complexity of shell formation. Nature 2012; 490: 49-54.

2. Francis MH, Brent F, Snimar G, Inna MS. Apoptosis as a host defense mechanism in Crassostrea virginica and its modulation by Perkinsus marinus. Fish Shellfish Immunol 2010; 29: 247-257.

3. Sokolova IM, Evans S, Hughes FM. Cadmium-induced apoptosis in oyster hemocytes involves disturbance of cellular energy balance but no mitochondrial permeability transition. J Exp Biol 2004; 207: 3369-3380.

4. Foster B, Grewal S, Graves O, Hughes FM, Sokolova IM. Copper exposure affects hemocyte apoptosis and Perkinsus marinus infection in eastern oysters Crassostrea virginica (Gmelin). Fish Shellfish Immunol 2011; 31: 341-349.

5. Renault T, Faury N, Barbosa-Solomieu V, Moreau K. Suppression substractive hybridisation (SSH) and real time PCR reveal differential gene expression in the Pacific cupped oyster, Crassostrea gigas, challenged with Ostreid herpesvirus 1. Dev Comp Immunol 2011; 35: 725-735.

6. Zhang L, Hou R, Su H, Hu X, Wang S, Bao Z. Network analysis of oyster transcriptome revealed a cascade of cellular responses during recovery after heat shock. Plos ONE 2012; 7: e35484.

7. Zhao X, Yu H, Kong L, Li Q. Transcriptomic responses to salinity stress in the Pacific Oyster Crassostrea gigas. Plos ONE 2012; 7: e46244-e46244.

8. Goldstein JC, Waterhouse NJ, Juin P, Evan GI, Green DR. The coordinate release of cytochrome $c$ during apoptosis is rapid, complete and kinetically invariant. Nat Cell Biol 2000; 2: $156-162$.

9. Peng L, Deepak N, Imawati B, Srinivasa MS, Manzoor A, Emad SA et al. Cytochrome c and dATP-dependent formation of Apaf-1/caspase- 9 complex initiates an apoptotic protease cascade. Cell 1997; 91: 479-489.

10. Kluck RM, Bossy-Wetzel E, Green DR, Newmeyer DD. The release of cytochrome c from mitochondria: a primary site for Bcl-2 regulation of apoptosis. Science 1997; 275: $1132-1136$.

11. Kluck RM, Seamus JM, Hoffman BM, Zhou JS, Green DR, Newmeyer DD. Cytochrome c activation of CPP32-like proteolysis plays a critical role in a Xenopus cell-free apoptosis system. Embo J 1997; 16: 4639-4649.

12. Robertson AJ, Croce J, Carbonneau S, Voronina E, Miranda E, Mcclay DR et al. The genomic underpinnings of apoptosis in Strongylocentrotus purpuratus. Dev Biol 2006; 300: 321-334.

13. Robb SMC, Eric R, Alejandro SA. SmedGD: the Schmidtea mediterranea genome database. Nucleic Acids Res 2008; 36: D599-D606.

14. Sullivan JC, Ryan JF, Watson JA, Webb J, Mullikin JC, Rokhsar D et al. StellaBase: the Nematostella vectensis genomics database. Nucleic Acids Res 2006; 34: D495-D499.

15. Wiens M, Krasko A, Müller Cl, Müller WE. Molecular evolution of apoptotic pathways: cloning of key domains from sponges (Bcl-2 homology domains and death domains) and their phylogenetic relationships. J Mol Evol 2000; 50: 520-531.

16. Hu Y, Ding L, Spencer DM, Núñez G. WD-40 repeat region regulates Apaf-1 self-association and procaspase-9 activation. J Biol Chem 1998; 273: 33489-33494.
17. Rodriguez A, Oliver H, Zou H, Chen P, Wang X, Abrams JM. Dark is a Drosophila homologue of Apaf-1/CED-4 and functions in an evolutionarily conserved death pathway. Nat Cell Biol 1999; 1: 272-279.

18. Bender CE, Patrick F, Tait SWG, Fabien L, Mcstay GP, Tupper DO et al. Mitochondrial pathway of apoptosis is ancestral in metazoans. Proc Natl Acad Sci USA 2012; 109: 4904-4909.

19. Lee EF, Clarke OB, Marco E, Zhiping F, Speed TP, Tchoubrieva EB et al. Discovery and molecular characterization of a Bcl-2-regulated cell death pathway in schistosomes. Proc Natl Acad Sci USA 2011; 108: 6999-7003.

20. Oberst A, Bender C, Green DR. Living with death: the evolution of the mitochondrial pathway of apoptosis in animals. Cell Death Differ 2008; 15: 1139-1146.

21. Zhang L, Li L, Zhang G. Gene discovery, comparative analysis and expression profile reveal the complexity of the Crassostrea gigas apoptosis system. Dev Comp Immunol 2011; 35: 603-610.

22. Tao $Q$, Baoyu $H$, Linlin Z, Li L, Fei $X$, Wen $H$ et al. Identification and functional characterization of two executioner caspases in Crassostrea gigas. Plos ONE 2014; 9: e89040.

23. Tao $Q$, Zhang L, Wei W, Huang B, Li Y, Zhu $Q$ et al. Characterization of an inhibitor of apoptosis protein in Crassostrea gigas clarifies its role in apoptosis and immune defense. Dev Comp Immunol 2015; 51: 74-78.

24. Alejandro R, Noelia EC, Sonia D, Antonio F, Beatriz N. New insights into the apoptotic process in mollusks: characterization of caspase genes in Mytilus galloprovincialis. Plos ONE 2011; 6: e17003.

25. Estévez-Calvar N, Romero A, Figueras A, Novoa B. Genes of the mitochondrial apoptotic pathway in Mytilus galloprovincialis. Plos ONE 2013; 8: e61502.

26. Margherita L, Barbara P, Nikola S, Mihai C, Beate S, Tina K et al. The molecular cell death machinery in the simple cnidarian Hydra includes an expanded caspase family and pro-and anti-apoptotic Bcl-2 proteins. Cell Res 2010; 20: 812-825.

27. Hsieh SY, Hsu CY, He JR, Liu CL, Lo SJ, Chen YC et al. Identifying apoptosis-evasion proteins/pathways in Human hepatoma cells via induction of cellular hormesis by UV irradiation. J Proteome Res 2009; 8: 3977-3986.

28. Zhang Z, Liu L, Wu S, Xing D. Drp1, Mff, Fis1, and MiD51 are coordinated to mediate mitochondrial fission during UV irradiation-induced apoptosis. FASEB J 2016; 30: 466-476.

29. Gervais O, Renault T, Arzul I. Induction of apoptosis by UV in the flat oyster, Ostrea edulis. Fish Shellfish Immunol 2015; 46: 232-242.

30. Von AO, Waterhouse NJ, Kuwana T, Newmeyer DD, Green DR. The 'harmless' release of cytochrome c. Cell Death Differ 2000; 7: 1192-1199.

31. Jürgensmeier JM, Krajewski S, Armstrong RC, Wilson GM, Oltersdorf T, Fritz LC et al. Bax- and Bak-induced cell death in the fission yeast Schizosaccharomyces pombe. Mol Biol Cell 1997; 8: 325-339.

32. Sattler M, Liang H, Nettesheim D, Meadows RP, Harlan JE, Eberstadt M et al. Structure of Bcl-xL-Bak peptide complex: recognition between regulators of apoptosis. Science 1997; 275: 983-986.

33. Rebeca M, Pablo B, Josep VP, Berta F, Sergi B, Beatriz N et al. Transcriptomics of in vitro immune-stimulated hemocytes from the manila clam Ruditapes philippinarum using high-throughput sequencing. Plos ONE 2012; 7: e35009.

34. Philipp EE, Kraemer L, Melzner F, Poustka AJ, Thieme S, Findeisen U et al. Massively parallel RNA sequencing identifies a complex immune gene repertoire in the lophotrochozoan Mytilus edulis. Plos ONE 2012; 7: e33091.

35. Boris Z, Guido K. Apoptosis and genomic instability. Nat Rev Mol Cell Biol 2004; 5: 752-762.

36. Varkey J, Chen P, Jemmerson R, Abrams JM. Altered cytochrome $\mathrm{c}$ display precedes apoptotic cell death in Drosophila. J Cell Biol 1999; 144: 701-710.

37. Dorstyn L, Read S, Cakouros D, Huh JR, Hay BA, Kumar S et al. The role of cytochrome c in caspase activation in Drosophila melanogaster cells. J Cell Biol 2002; 156: 1089-1098.

38. Zimmermann KC, Ricci JE, Droin NM, Green DR. The role of ARK in stress-induced apoptosis in Drosophila cells. J Cell Biol 2002; 156: 1077-1087.

39. Sato M, Matsushima K, Kawanami H, Ikuhsima Y. The two cytochrome c species, DC3 and DC4, are not required for caspase activation and apoptosis in Drosophila cells. J Cell Biol 2004; 167: 405-410.

40. Ranger AM, Malynn BA, Korsmeyer SJ. Mouse models of cell death. Nat Genet 2001; 28: 113-118.

41. Hu Y, Ding L, Spencer DM, Núñez G. WD-40 repeat region regulates Apaf-1 self-association and procaspase-9 activation. J Biol Chem 1998; 273: 33489-33494.

42. Hsu YT, Wolter KG, Youle RJ. Cytosol-to-membrane redistribution of Bax and Bcl-XL during apoptosis. Proc Natl Acad Sci USA 1997; 94: 3668-3672.

43. Wolter KG, Hsu YT, Smith CL, Nechushtan A, Xi XG, Youle RJ. Movement of Bax from the cytosol to mitochondria during apoptosis. J Cell Biol 1997; 139: 1281-1292.

44. Dhyan C, Grace C, Daniel PT, Tang DG. Bax-dependent regulation of Bak by voltage-dependent anion channel 2. J Biol Chem 2005; 280: 19051-19061.

45. Li Y, Zhang L, Qu T, Li L, Zhang G. Characterization of oyster voltage-dependent anion channel 2 (VDAC2) suggests its involvement in apoptosis and host defense. Plos ONE 2016; 11: e0146049.

46. Chipuk JE, Moldoveanu T, Llambi F, Parsons MJ, Green DR. The BCL-2 family reunion. Mol Cell 2010; 37: 299-310.

47. Bonsu K, Chengyu L, Jung JU, Byung-Ha O. Evidence that inhibition of BAX activation by $\mathrm{BCL}-2$ involves its tight and preferential interaction with the $\mathrm{BH} 3$ domain of $\mathrm{BAX}$. Cell Res 2011; 21: 627-641. 
48. Speidel D. Transcription-independent p53 apoptosis: an alternative route to death. Trends Cell Biol 2010; 20: 14-24.

49. Zhang L, Li L, Guo X, Litman GW, Dishaw LJ, Zhang G. Massive expansion and functional divergence of innate immune genes in a protostome. Sci Rep 2015; 5: 8693.

50. Li C, Tao Q, Huang B, Peng J, Wen H, Que $\mathrm{H}$ et al. Cloning and characterization of a novel caspase-8-like gene in Crassostrea gigas. Fish Shellfish Immunol 2015; 46: 486-492.

51. Leist M, Marja J. Four deaths and a funeral: from caspases to alternative mechanisms. Nat Rev Mol Cell Biol 2001; 2: 589-598.

52. Feng Y, Yang Z, Ziniu Y. Characteristics and expression patterns of the lipopolysaccharideinduced TNF- $\alpha$ factor (LITAF) gene family in the Pacific oyster, Crassostrea gigas. Fish Shellfish Immunol 2012; 33: 899-908.

53. Du Y, Zhang L, Huang B, Guan X, Li L, Zhang G. Molecular cloning, characterization, and expression of two myeloid differentiation factor 88 (Myd88) in Pacific Oyster, Crassostrea gigas. J World Aquacult Soc 2013; 44: 759-774. cc) (i) Cell Death and Disease is an open-access journal published by Nature Publishing Group. This work is licensed under a Creative Commons Attribution 4.0 International License. The images or other third party material in this article are included in the article's Creative Commons license, unless indicated otherwise in the credit line; if the material is not included under the Creative Commons license, users will need to obtain permission from the license holder to reproduce the material. To view a copy of this license, visit http://creativecommons.org/licenses/by/4.0/

(C) The Author(s) 2017

Supplementary Information accompanies this paper on Cell Death and Disease website (http://www.nature.com/cddis) 